\title{
A Detailed Testing Procedure of Numerical Differential Protection Relay for EHV Auto Transformer
}

\author{
Umer Ehsan ${ }^{1,2} \mathbb{D}$, Muhammad Jawad ${ }^{1, *(\mathbb{D}}$, Umar Javed ${ }^{1,3} \mathbb{D}^{\mathbb{D}}$, Khurram Shabih Zaidi ${ }^{1} \mathbb{D}$, Ateeq Ur Rehman ${ }^{4}(\mathbb{D}$, \\ Anton Rassõlkin ${ }^{5}$ (D), Maha M. Althobaiti ${ }^{6}$ (D) Habib Hamam ${ }^{7,8,9}$ and Muhammad Shafiq ${ }^{10, *(D)}$
}

1 Department of Electrical and Computer Engineering, Lahore Campus, COMSATS University Islamabad, Islamabad 54000, Pakistan; umer.ehsan@yahoo.com (U.E.); umarjaved636@gmail.com (U.J.); kzaidi@cuilahore.edu.pk (K.S.Z.)

2 National Transmission and Despatch Company Limited, Lahore 54000, Pakistan

3 Riphah College of Science and Technology, Lahore Campus, Riphah International University, Islamabad 54000, Pakistan

4 Department of Electrical Engineering, Government College University, Lahore 54000, Pakistan; ateqrehman@gmail.com

5 Department of Electrical Power Engineering \& Mechatronics, Tallinn University of Technology, 12616 Tallinn, Estonia; anton.rassolkin@taltech.ee

6 Department of Computer Science, College of Computing and Information technology, Taif University, P.O. Box 11099, Taif 21944, Saudi Arabia; Maha_m@tu.edu.sa

7 Faculty of Engineering, Uni de Moncton, Moncton, NB E1A 3E9, Canada; habib.hamam@umoncton.ca

8 Spectrum of Knowledge Production \& Skills Development, Sfax 3027, Tunisia

9 Department of Electrical and Electronic Engineering Science, School of Electrical Engineering, University of Johannesburg, Johannesburg 2006, South Africa

check for updates

Citation: Ehsan, U.; Jawad, M.; Javed, U.; Shabih Zaidi, K.; Ur Rehman, A.; Rassõlkin, A.; Althobaiti, M.M.; Hamam, H.; Shafiq, M. A Detailed Testing Procedure of Numerical Differential Protection Relay for EHV Auto Transformer. Energies 2021, 14, 8447. https:// doi.org/10.3390/en14248447

Academic Editor: Anna Richelli

Received: 4 November 2021

Accepted: 9 December 2021

Published: 14 December 2021

Publisher's Note: MDPI stays neutral with regard to jurisdictional claims in published maps and institutional affiliations.

Copyright: (c) 2021 by the authors. Licensee MDPI, Basel, Switzerland. This article is an open access article distributed under the terms and conditions of the Creative Commons Attribution (CC BY) license (https:/ / creativecommons.org/licenses/by/ $4.0 /)$.
10 Department of Information and Communication Engineering, Yeungnam University, Gyeongsan 38541, Korea

* Correspondence: mjawad@cuilahore.edu.pk (M.J.); shafiq@ynu.ac.kr (M.S.)
Abstract: In power systems, the programmable numerical differential relays are widely used for the protection of generators, bus bars, transformers, shunt reactors, and transmission lines. Retrofitting of relays is the need of the hour because lack of proper testing techniques and misunderstanding of vital procedures may result in under performance of the overall protection system. Lack of relay's proper testing provokes an unpredictability in its behavior, that may prompt tripping of a healthy power system. Therefore, the main contribution of the paper is to prepare a step-by-step comprehensive procedural guideline for practical implementation of relay testing procedures and a detailed insight analysis of relay's settings for the protection of an Extra High Voltage (EHV) auto transformer. The experimental results are scrutinized to document a detailed theoretical and technical analysis. Moreover, the paper also covers shortcomings of existing literature by documenting specialized literature that covers all aspects of protection relays, i.e., from basics of electromechanical domain to the technicalities of the numerical differential relay covering its detailed testing from different reputed manufacturers. A secondary injection relay test set is used for detailed testing of differential relay under test, and the S1 Agile software is used for protection relay settings, configuration modification, and detailed analysis.

Keywords: current transformers; current measurement; power system protection; power transformers; relays; testing

\section{Introduction}

In modern Extra High Voltage (EHV) power networks, the protection of the power system is continuously being upgraded by the replacement of old electromechanical protection relays with the new microprocessor based numerical protection relays known as Intelligent Electronic Devices (IEDs). Retrofitting of numerical protection relays is essential and currently an ongoing process throughout power transmission networks. If it is not 
properly configured and tested or the settings are inappropriate due to lack of its technical knowledge, then the relay can exhibit unpredictable behavior [1]. Due to the fact, the relay may not sense faulty conditions at all or may cause tripping in a healthy condition. Such behavior of numerical protection relay is highly undesirable and ultimately results in frequent outages in power systems along with massive revenue loss. To mitigate such undesired situations and system disturbances, it is necessary to conduct their detailed testing.

The power system under test is a three-phase solidly grounded, with a maximum nominal phase-to-phase voltage level equal to $500 \mathrm{kV}$. The generation voltage is less than or equal to $23 \mathrm{kV}$ and is stepped up to the desired transmission voltage level through station transformers. The transmission voltage is either 500 or $220 \mathrm{kV}$. To step down voltage level from 500 to $220 \mathrm{kV}$ and from 220 to $132 \mathrm{kV}$, auto transformers are employed. Moreover, the $132 \mathrm{kV}$ voltage level is stepped down to $11.5 \mathrm{kV}$ through conventional power transformer. The SLD of the system showing all voltage levels is depicted in Figure 1 [2]. In an existing power system of Pakistan, two differential relays named as main differential relay and rough balance differential relay are installed for protection of $500 \mathrm{kV} / 220 \mathrm{kV}$ auto transformer and $220 \mathrm{kV} / 132 \mathrm{kV}$ auto transformer, respectively [3]. Through continuous monitoring of the protection relays, it is ensured that any undesired situation or fault is dealt with using proper response and the faulty portion is isolated from the healthy system with high speed, accuracy, selectivity, and reliability.

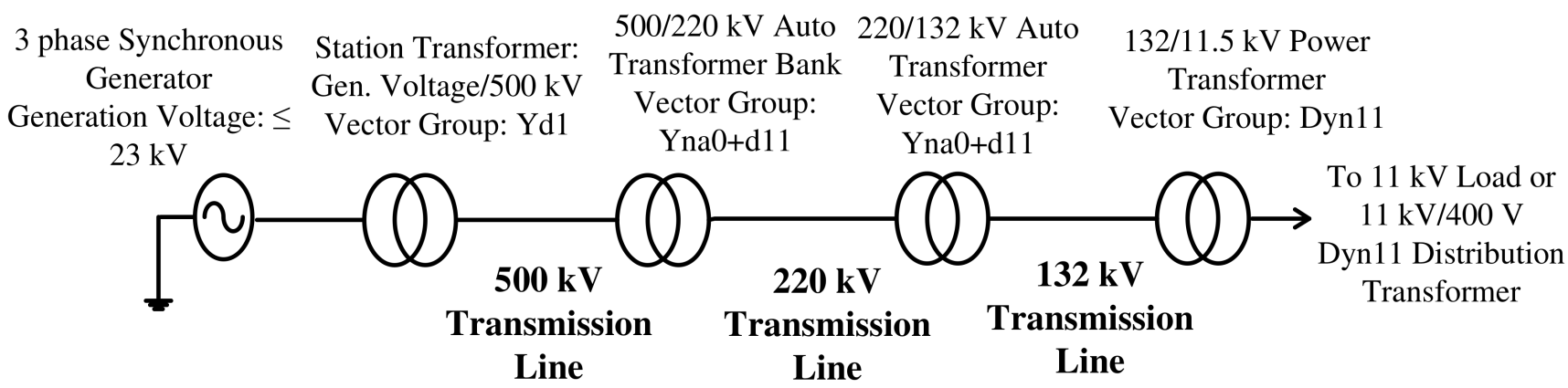

Figure 1. Single line diagram showing all voltage levels of the power system in Pakistan [2].

In the literature, very few research articles are published that discuss theoretical details of IEDs and different testing techniques. In [4], theoretical aspects in testing of the microprocessor based numerical protection relays are discussed. The author discusses the concepts, such as vector group of transformers, interposing CTs, and zero sequence filtering in detail. Moreover, the authors also describe the concepts for pickup test and bias characteristics test. However, the paper lacks a double phase pickup test and harmonic restraint testing of numerical differential relay that are of vital importance. In [5], a study of differential relay is presented considering power system disturbances and the behavior of the numerical differential relay is analyzed in detail; however, its exact threshold settings and set points are not verified. A novel technique for determining the settings of numerical differential relay is proposed in [6]. The authors have used a software-based simulator that utilizes iterations for the determination of settings. Furthermore, enhancement techniques for power transformer differential protection are described in [7], in which the author also discussed internal and external fault cases for differential protection and conducted a simulation testing through real-time digital simulation.

The actuation of transformer differential protection is conditional to the presence of existing internal transformer faults that may deteriorate a transformer's health. Several methods have been developed to perform condition monitoring of a transformer's health [8]. One such method is Frequency Response Analysis (FRA), which deals with analyzing the frequency response of a transformer on application of signal with frequency ranging from several hundred to several mega Hertz (low, mid, and high frequency bands) and compares it with the pre-commissioning or factory testing signal of transformers. In [8], 
the authors provide comprehensive guidelines for interpretation and evaluation of FRA of transformers. Moreover, in [9], the authors discuss valuable insight on understanding FRA signatures and the effect of several transformer faults on FRA signature. The faults include axial displacement, bushing fault, radial deformation, loss of clamping pressure, inter-disk fault, and short circuit fault.

To the best of the author's knowledge, there is no formal guideline and detailed study available to the research community and power system protection experts that thoroughly discusses the testing procedures for numerical differential relays as a single document. Therefore, to fill this literature gap, the main purpose of this research work is to prepare and compose a step-by-step detailed manual that can provide a complete guideline for the practical implementation of relay testing procedures and thorough numerical analysis that one can follow to check the health and functionality of a differential protection relay installed at EHV auto transformer. A real-time result analysis is performed on the differential relay installed for protection of 160 MVA, 220/132 kV Auto Transformer located at $220 \mathrm{kV}$ Grid Station NTDC Kala Shah Kaku, Lahore, Pakistan. The experimental results are scrutinized to document a detailed theoretical and technical analysis. In light of the above stated actualities, the main contributions of the paper are:

- Detailed insight analysis of numerical differential relay settings including connection details, operating principle, and biasing characteristics. Moreover, important transformer considerations are also discussed.

- A detailed testing procedure of numerical differential relay is conducted through secondary injection testing with actual settings. The testing results include measurement test, pickup test, trip-time test, stability test, bias characteristics test, 2nd and 5th harmonic restraints test, and high stage 1 and high stage 2 test.

- A detailed theoretical and technical analysis is conducted and documented to analyze the practical results.

The remaining paper is organized as follows: Section 2 discusses differential relay architecture and differential relay considerations for transformer application briefly. Section 3 focuses towards Matching Current Transformers or Interposing Current Transformers. The key settings implemented in the relay under test are described in Section 4. Section 5 discusses the testing of differential relay in detail. Section 6 focuses on a result discussion of the tests performed. The paper is concluded in Section 7 along with future suggestions.

\section{Differential Relay}

Figure 2a shows the single line diagram for connections of differential relay based on Kirchhoff's current law [10]. In Figure 2a, the current transformers are used as current sensors that essentially stepdown current with high fidelity [11]. The relay receives input from CTs, and continuously monitors and compares current. If any mismatch is observed beyond the defined setting, then the trip command is initiated, which isolates the protected object from the power system. Differential relay compares the magnitude and phase angle of the currents available at its terminals and remains stable if the vector sum of compared currents is less than the threshold setting in its internal differential coils [5]. Figure $2 b$ explains the single-phase schematic drawing for basic operating principle of the differential relay. The comparison or vector sum is performed in the differential coil $\mathrm{C}$ of the relay and resultant current is called differential current $I_{\text {diff }}$. The $I_{\text {diff }}$ is zero if vector sum of currents from side A $\left(I_{A}\right)$ and side $\mathrm{B}\left(I_{B}\right)$ is zero. The minimum value of the differential current $I_{\text {diff }}$ at which the relay operates is controlled by a setting called $I_{\text {diff }}$ pickup. A minute spill current normally flows through the relay due to the CT errors and losses [12].

In Figure $2 b$, the restraining coils A and B are also called biasing coils. As the current through protected equipment increases, for example in case of through fault, spill current increases proportionally. The relay may operate during through fault due to spill current since the $I_{\text {diff }}$ pickup was the only setting of the differential relay, which is highly undesirable. To mitigate this issue, restraining or biasing is provided based on the loading condition of the protected object through restraining coils, and their setting results in 
percentage bias characteristics (slope characteristics) of the relay, which essentially results in restraining the operation of the relay [13]. The restraint (biasing) characteristics provide stability to the differential relay during normal and through fault scenarios; therefore, the differential relays are called percentage biased differential relays.

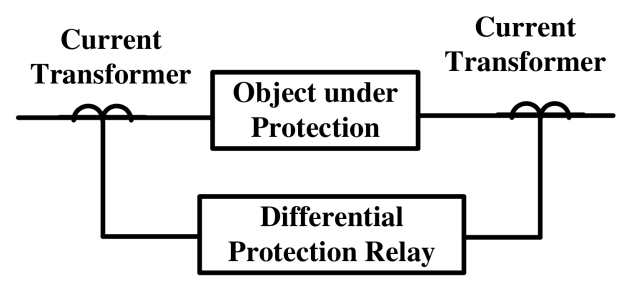

(a)

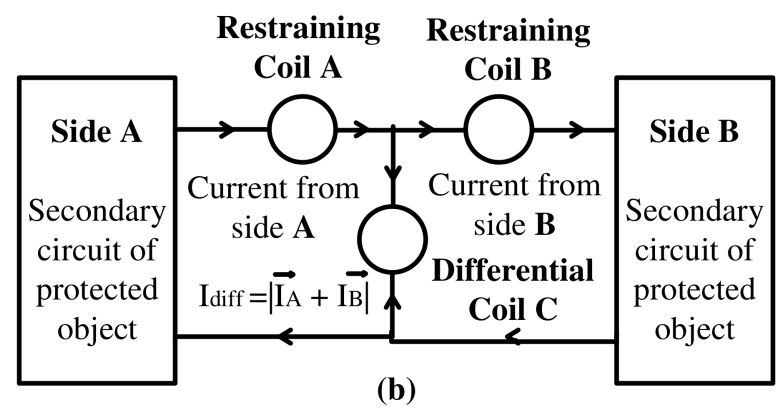

(b)

Figure 2. Differential protection relay: (a) single line diagram with connections [10] and (b) basic operating principle [13].

\section{Transformers}

A transformer is a static electric machine and works on electromagnetic induction principles. It is used to transfer power from one voltage level to another one while maintaining electrical isolation between different voltage levels and can be controlled by varying the number of turns of each winding. However, the voltage per turn ratio remains constant across its windings. The nominal current of each winding can be calculated by using Equation (1) [4].

$$
I_{\text {nom }}=\frac{\text { Power } \text { Rating }_{K V A}}{\sqrt{3} \times P h-P h \text { Voltage rating } \text { KVV }_{\text {P }}}
$$

The transformers occupy less geographical area that makes them well suited to be protected through differential protection. The differential protection has a very crisp and well-defined zone of protection. The zone of protection is between the CTs that are feeding the differential relay. Some important considerations regarding transformers must be considered before further delving into application of differential relay for the protection of transformers. In a nutshell, the transformer differential relay must cater for the following characteristics of a transformer.

- Differential relay should cater Vector Group of Transformer [14,15], Zero Sequence Current Flows [16], On Load Tap Changers [17], and must not initiate tripping during normal operation of transformer including energization of transformer (Inrush Current [18,19]), over fluxing [20], and tap changer operation.

- Differential relay should remain stable during through fault even if the CT saturation of one or more CTs occur [21,22].

- Differential relay should only initiate tripping during in-zone fault (fault inside protection zone of differential relay [23]).

\section{Matching Current Transformers of Interposing Transformers}

When no fault occurs in the differential protection zone during normal operation of a transformer, the current in differential coils of the differential relay should be equal in magnitude but with 180-degree phase shift. However, secondary currents from CTs mostly differ in magnitude and phase angle; therefore, the secondary currents cannot be directly applied to the differential coils of the relay and are conditioned and modified before applying to them so that the relay remains stable (ideally $I_{\text {diff }}=0$ ) during the transformer's normal operation. The conditioning and matching of CT secondary currents are performed through Matching Current Transformers (MCT) or Interposing CT [4]. The matching CTs also performs zero-sequence filtering whenever required in the secondary circuit. 
Figure 3a shows the connection diagram of the differential relay with two windings of the transformer. The transformer under consideration is $220 / 132 / 11 \mathrm{kV}, 160 / 160 / 30 \mathrm{MVA}$ auto transformer with vector group Yna0 $+\mathrm{d} 11$. High voltage side (primary winding) terminals are marked as A, B, and C while the secondary winding terminals (132 kV side) are marked as $\mathrm{Am}, \mathrm{Bm}$, and $\mathrm{Cm}$. The neutral terminal is grounded and marked as $\mathrm{O}$. Tertiary winding terminals ( $11 \mathrm{kV}$ side) are marked as a, b, $\mathrm{x}$, and c. Tertiary delta is unloaded, kept close through external jumper between terminal $\mathrm{x}$ and terminal $\mathrm{c}$ and is not wired to the differential relay. The external jumper between terminals $\mathrm{x}$ and $\mathrm{c}$ is connected to ground.

The secondary side of both main CTs is star connected and the star point is towards the auto transformer and is grounded at one point only. The secondary CT circuit from 220 and $132 \mathrm{kV}$ side terminates into the current elements of the differential relay as shown in Figure 3a. The dotted box marked as " $\mathrm{D}$ " inside differential relay contains MCTs, restraining coils, differential coils, and harmonic restraining coils. In modern differential relays, all such coils are implemented through an algorithm. Matching CT's configuration and vector group depends on transformer under protection and may vary from manufacturer to manufacturer as per their protection design. Figure $3 b$ shows the inside architecture of the dotted box D from Figure 3a [24]. The red (R), yellow (Y), blue (B), and neutral (N) currents from HV CT secondary side is shown as $I_{H V ~ s e c-R}, I_{H V ~ s e c-\gamma}, I_{H V ~ s e c-B}$, and $I_{H V ~ s e c-N}$, respectively. Similarly, for the LV CT secondary side they are shown as $I_{L V} \mathrm{sec}-R$, $I_{L V ~ s e c-\gamma}, I_{L V ~ s e c-B}$, and $I_{L V ~ s e c-N}$, respectively. Both HV and LV side MCT is in star-deltastar configuration. The delta winding traps the zero-sequence current. In this particular case, both HV and LV MCT are used for magnitude compensation and phase introduced by them will be 0 . MCT configurations for relay type P642 under different vector groups of transformers are as follows.

\section{Auto Transformer Yna0+d11 \\ $220 \mathrm{kV} / 132 \mathrm{kV} / 11 \mathrm{kV}$ \\ 160 MVA / 160 MVA / 30 MVA}

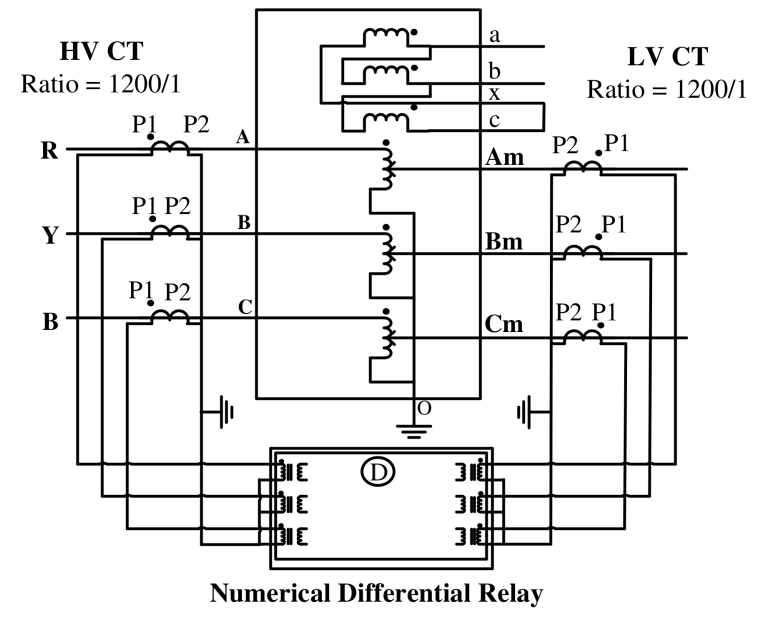

(a)

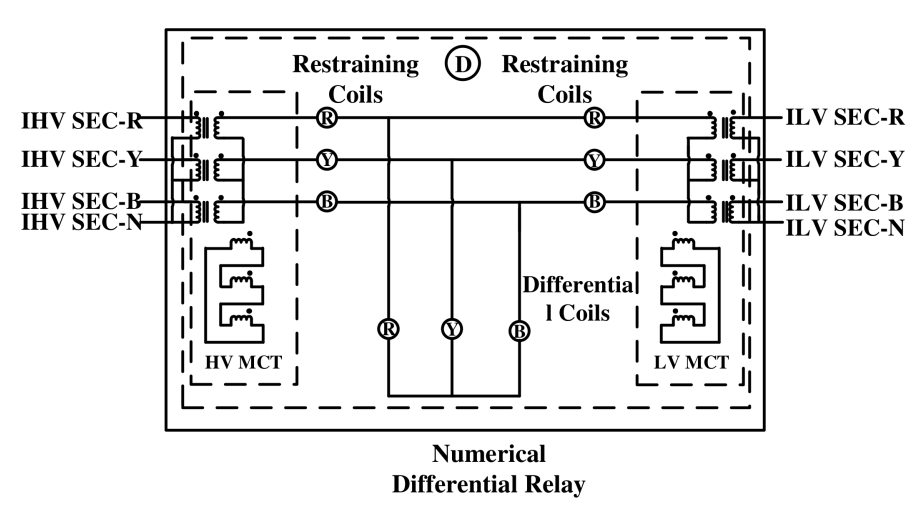

(b)

Figure 3. Differential relay circuit [24]: (a) connection diagram with two windings of transformer, and (b) matching CTs, restraining coils, and differential coils implemented in differential relay through algorithm.

\section{1. $H V M C T$}

Transformer HV side matching CTs, irrespective of transformer's vector group under protection are of either star-delta-star or star-star configuration. Star-delta-star configuration is used for magnitude compensation and zero sequence filtering whereas star-star configuration performs magnitude compensation only. 


\section{2. $L V M C T$}

If the main transformer has a vector group of $\mathrm{YyX}$ or $\mathrm{DdX}$ (where $\mathrm{X}$ is any even integer from 0 to 11 indicating phase shift between HV and LV windings), then LV MCT will be star-star Z (when zero sequence current filtering is disabled) or star-delta-star Z (when zero sequence current filtering is enabled). The $Z$ is the phase shift introduced by LV MCT for the compensation of phase shift introduced by the vector group of the main transformer. The delta is only introduced when zero sequence current filtering is required. Similarly, if the main transformer has vector group of $\mathrm{YdX}$ or DyX (where $\mathrm{X}$ is any odd integer from 1 to 11 showing phase shift between primary and secondary winding), then LV MCT will be star-delta Z. LV MCT provides necessary phase compensation in addition to the magnitude compensation and zero-sequence filtering (if required). Table 1 shows different vector groups of transformer and corresponding LV MCT configuration with required phase shift when the vector group of transformers under protection is $\mathrm{YyX}, \mathrm{DdX}, \mathrm{YdX}$, or DyX.

Table 1. LV MCT vector group configuration for transformers: (A) with vector group YyX or DdX, (B) transformers with vector group YdX or DyX.

\begin{tabular}{ccccc}
\hline \multirow{2}{*}{ Sr. No. } & \multicolumn{2}{c}{ (A) VG YyX or DdX } & \multicolumn{2}{c}{ (B) VG YdX or DyX } \\
\cline { 2 - 5 } & $\begin{array}{c}\text { Transformer } \\
\text { Vector Group }\end{array}$ & $\begin{array}{c}\text { LV MCT Vector } \\
\text { Group }\end{array}$ & $\begin{array}{c}\text { Transformer } \\
\text { Vector Group }\end{array}$ & $\begin{array}{c}\text { HV MCT Vector } \\
\text { Group }\end{array}$ \\
\hline 1 & Yy0 or Dd0 & Yy0 & Yd1 or Dy1 & Yd11 \\
2 & Yy2 or Dd2 & Yy10 & Yd3 or Dy3 & Yd9 \\
3 & Yy4 or Dd4 & Yy8 & Yd5 or Dy5 & Yd7 \\
4 & Yy6 or Dd6 & Yy6 & Yd7 or Dy7 & Yd5 \\
5 & Yy8 or Dd8 & Yy4 & Yd9 or Dy9 & Yd3 \\
6 & Yy10 or Dd10 & Yy2 & Yd11 or Dy11 & Yd1 \\
\hline
\end{tabular}

\section{Settings Implemented in Differential Relay}

The S1 Agile software is used for implementation of settings in differential relay P642 (Make: Alstom [24]) [25]. The CT ratio data, transformer data, and differential relay settings implemented in the differential relay are shown in Tables 2-4, respectively. In Table 4, the

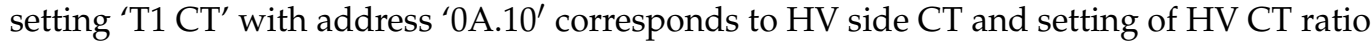
is 1200:1. The setting 'Polarity' is set to 'standard' that shows the star point of HV CT is

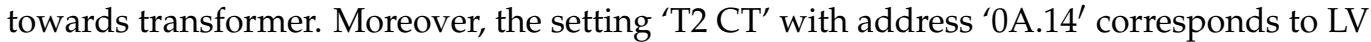
side CT and setting of LV CT Ratio is also 1200:1. The setting 'Polarity' is set to 'standard' that shows the star point of the LV CT is towards the transformer.

Table 2. CT data implementation in differential relay on 220 kV GS KSK 160 MVA transformer T2.000.

\begin{tabular}{ccc}
\hline CT and VT Ratios & Value & Address (C.R) \\
\hline Aux' VT Location & $\mathrm{HV}$ & $0 \mathrm{~A} .02$ \\
Aux' VT Primary & $220.0 \mathrm{kV}$ & $0 \mathrm{~A} .07$ \\
Aux' VT Sec' y & $110.0 \mathrm{~V}$ & $0 \mathrm{~A} .08$ \\
T1 CT & & $0 \mathrm{~A} .10$ \\
Polarity & Standard & $0 \mathrm{~A} .11$ \\
Primary & $1200 \mathrm{~A}$ & $0 \mathrm{~A} .12$ \\
Secondary & $1.000 \mathrm{~A}$ & $0 \mathrm{~A} .13$ \\
T2 CT & & $0 \mathrm{~A} .14$ \\
Polarity & Standard & $0 \mathrm{~A} .15$ \\
Primary & $1200 \mathrm{~A}$ & $0 \mathrm{~A} .16$ \\
Secondary & $1.000 \mathrm{~A}$ & $0 \mathrm{~A} .17$ \\
\hline
\end{tabular}


Table 3. Auto transformer implementation in relay.

\begin{tabular}{ccc}
\hline CT and VT Ratios & Value & Address (C.R) \\
\hline Winding Type & Auto & 30.02 \\
HV CT Terminals & 01 & 30.03 \\
LV CT Terminals & 10 & 30.04 \\
Ref Power S & $160.0 \mathrm{MVA}$ & 30.07 \\
HV Connection & Y-Wye & 30.08 \\
HV Grounding & Grounded & 30.09 \\
HV Nominal & $220.0 \mathrm{kV}$ & $30.0 \mathrm{~A}$ \\
HV Rating & $160.0 \mathrm{MVA}$ & $30.0 \mathrm{~B}$ \\
Percentage Reactance & $25.00 \%$ & $30.0 \mathrm{C}$ \\
LV Vector Group & 0 & $30.0 \mathrm{D}$ \\
LV Connection & Y-Wye & $30.0 \mathrm{E}$ \\
LV Grounding & Grounded & $30.0 \mathrm{~F}$ \\
LV Nominal & $132.0 \mathrm{kV}$ & 30.10 \\
LV Rating & $160.0 \mathrm{MVA}$ & 30.11 \\
Match Factor CT1 & 2.858 & 30.20 \\
Match Factor CT2 & 1.715 & 30.21 \\
Phase Sequence & Standard ABC & $30.5 \mathrm{E}$ \\
\hline
\end{tabular}

Table 3 corresponds to auto transformer data implemented in the differential relay. Power rating of both HV and LV winding is set to 160 MVA. The HV and LV connection of the auto transformer are in ' $Y$ '. The HV nominal voltage rating and $L V$ nominal voltage rating are 220 and $132 \mathrm{kV}$, respectively. The neutral of $\mathrm{HV}$ and LV winding is considered as 'grounded'. Figure 4 shows the graphical differential characteristics or bias characteristics implemented for the testing. The setting 'Trans Diff' is set to 'enabled', which means that the differential protection function is enabled in the relay. In Table 4 and Figure 4, the current $I_{S 1}$ is pick-up setting of the differential relay. Setting 'K1' in Table 4 and Figure 4 is the percentage slope for the slope 2 of differential characteristics. The slope provides restraining of differential protection operation in case of spill current occurrence due to the tap changing operation, CT errors, and through faults. The differential relay must remain stable and must not initiate tripping during through faults. However, the CT errors may result in larger mismatched current or spill current or differential current as defined in Figure $2 b$, which depends on fault intensity. In such cases, the restraining to differential operation is provided through slope setting ' $\mathrm{K} 1=30 \%$ '. Slope is the ratio of change in differential current to the change in bias current.

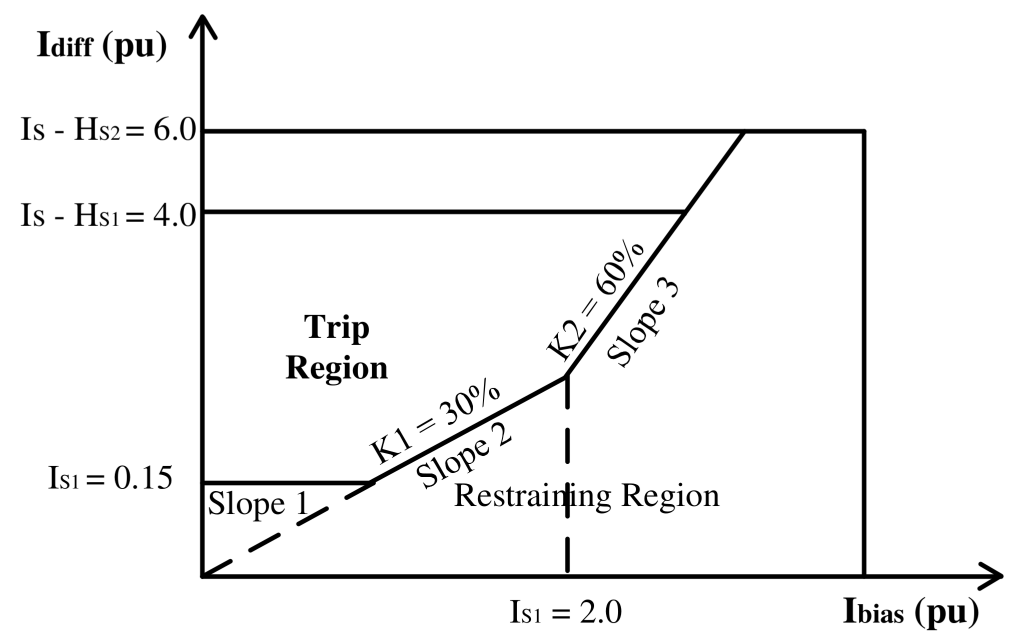

Figure 4. Differential characteristics or bias characteristics implemented in relay. 
Table 4. Differential protection settings implementation in relay.

\begin{tabular}{ccc}
\hline CT and VT Ratios & Value & Address (C.R) \\
\hline Trans Diff & Enabled & 31.01 \\
Set Mode & Advanced & 31.02 \\
$I_{S 1}$ & $150 \times 10^{-3} \mathrm{PU}$ & 31.03 \\
K1 & $30.00 \%$ & 31.04 \\
$I_{S 2}$ & $2.000 \mathrm{PU}$ & 31.05 \\
K2 & $60.00 \%$ & 31.06 \\
tDIFF LS & $0 \mathrm{~s}$ & 31.07 \\
$I_{S}-$ CTS & $250 \times 10^{-3} \mathrm{PU}$ & 31.08 \\
$I_{S}-H_{S 1}$ & $4.000 \mathrm{PU}$ & 31.10 \\
$H_{S 2}$ Status & Enabled & 31.11 \\
$I_{S}-H_{S 2}$ & $6.000 \mathrm{PU}$ & 31.12 \\
Zero seq. filt. HV & Enabled & 31.20 \\
Zero seq. filt. LV & Enabled & 31.21 \\
2nd harmonic blocked & Enabled & 31.28 \\
$I_{h}(2) \%>$ & $15.00 \%$ & 31.29 \\
Cross blocking & Enabled & $31.2 \mathrm{~A}$ \\
CT-Sat and No-Gap & Enabled & $31.2 \mathrm{~B}$ \\
5th harmonic blocked & Enabled & 31.33 \\
$I_{h}(5) \%>$ & $40.00 \%$ & 31.34 \\
Circuitry fail & Disabled & 31.40 \\
\hline
\end{tabular}

In Table 4, the setting $I_{S 2}$ marks the start of slope 3, as shown in Figure 4 . The slope 3 provides restraining of differential protection, during through fault, even if the main $\mathrm{CT}$ is saturated. The setting ' $\mathrm{K} 2$ ' in Table 4 and Figure 4 defines the percentage slope setting for slope 3. The setting ' $I_{S}-H_{S 1}$ ' in Table 4 and Figure 4 monitors the operational peak of the differential current. Beyond setting ' $I_{S}-H_{S 1}$ ', the 2nd harmonic restrain cannot restrain differential relay operation. Therefore, the setting should be kept higher than expected peak magnetizing current. Setting ' $I_{S}-H_{S 1}$ ' only results in tripping if the peak value of the differential current exceeds ' $I_{S}-H_{S 1}$ ' setting and operating point lies in trip region of the bias characteristics. If differential current exceeds the setting ' $I_{S}-H_{S 2}$ ', as shown in Table 4 and Figure 4, the differential relay causes tripping regardless of biasing characteristics and harmonic components. The differential relay continuously calculates $I_{\text {diff }}$ and $I_{\text {bias }}$ current through HV and LV secondary currents at its terminals. If the calculated $I_{\text {diff }}$ and $I_{\text {bias }}$ currents end up in the tripping region, the differential relay will initiate tripping as per the defined algorithm. Setting 'Zero sequence filtering, $\mathrm{HV}^{\prime}$ ' and 'Zero sequence filtering $\mathrm{LV}^{\prime}$ set to 'Enabled' will result in the elimination of zero sequence current components through HV and LV MCTs. The 2nd, 5th harmonic blocking are set at $15 \%$ and $40 \%$, respectively.

\section{Testing of Differential Relay}

\subsection{Test Apparatus}

Testing of the differential relay is conducted through a six current source secondary injection universal relay test set connected to the relay, as shown in Figure $5 a, b$. The settings and configuration of the relay is performed through S1 Agile Software, and the computer is used for reference setting and result monitoring. The relay trip contact is used as stop contact for the test set.

\subsection{Measurement Test}

A measurement test is performed to ascertain that the relay is reading the current at its terminals accurately. Through the measurement test, the correctness of CT ratios and measurement of differential and restraining current is determined (in pu). The nominal current or full load current at primary and secondary side of the transformer is calculated using Equation (1) as $\mathrm{I}_{\text {nom.pri }}=420 \mathrm{~A}$ and $\mathrm{I}_{\text {nom. sec }}=700 \mathrm{~A}$. The CT ratio at primary and secondary side of the transformer is computed as [4]: 


$$
\begin{gathered}
\text { CT Ratio }=\frac{\text { Rated Primary Current }}{\text { Rated Secondary Current }}=\frac{1200}{1}=1200 \\
\mathrm{I}_{\text {nom.pri. sec }}=\frac{\mathrm{I}_{\text {nom.pri }}}{\text { CT Ratio }}=\frac{420}{1200}=0.35 \\
\mathrm{I}_{\text {nom. sec. sec }}=\frac{\mathrm{I}_{\text {nom. sec }}}{\text { CT Ratio }}=\frac{700}{1200}=0.58
\end{gathered}
$$

Referring to Figure $2 b$, the differential current is computed as vector sum of currents flowing through it as [4]:

$$
\mathrm{I}_{\text {diff }}=\left|\overrightarrow{\mathrm{I}_{1}}+\overrightarrow{\mathrm{I}_{2}}\right|
$$

where $\mathrm{I}_{1}$ and $\mathrm{I}_{2}$ are the secondary current of HV MCT and LV MCT, respectively, that are shown as $I_{A}$ and $I_{B}$ in Figure $2 b$. The $\vec{I}_{1}$ and $\vec{I}_{2}$ are vector quantity currents flowing in the differential coil. Restraining current or bias current provides restrain to the differential relay operation [26]. The bias current is based on the loading of the transformer and hampers the operation of the relay. However, the bias current computation in differential relay differs in different makes and models, and even the same manufacturer may have different mathematical equation for its computations. Bias current is computed in Equation (6) as follows [4]:

$$
\mathrm{I}_{\text {bias }}=\frac{\left|\mathrm{I}_{1}\right|+\left|\mathrm{I}_{2}\right|}{2}
$$

Both the differential and bias currents are measured as per unit quantities, where per unit value is the ratio of actual and base values. The base value is the rated secondary current of the main CTs that in our case is taken as 1A. Whereas, the HV MCT ratio and LV MCT ratio are automatically calculated by differential relay as 2.858 and 1.715 , respectively, using Equation (7) [4].

$$
\text { HV MCT Ratio or LV MCT Ratio }=\mathrm{a}=\frac{\mathrm{I}_{\text {sec ondary }}}{\mathrm{I}_{\text {primary }}}
$$

Referring to Figure 6a and using HV MCT Ratio, we can illustrate that upon the injection of balanced three phase nominal HV secondary current $(0.35 \mathrm{~A})$ into corresponding relay current elements with no current injection into $\mathrm{LV}$ side relay current elements, current equal to $1 A$ flows in secondary of HV MCT, resulting in flow of $I_{\text {diff }}=1 \mathrm{pu}$ using Equation (5) and $I_{b i a s}=0.5 \mathrm{pu}$ using Equation (6). In Figure 6a, the phase shift of three phases is shown through clock convention, where 0 corresponds to $0^{\circ}, 4$ corresponds to $-120^{\circ}$, and 8 corresponds to $-240^{\circ}$. Therefore, in order to thoroughly verify the HV side relay elements measurement, HV secondary current corresponding to the different loading conditions is simulated and then by computing HV primary current values. Moreover, the differential current and bias current are compared with observed values. Tables 5 and 6 record the measurement results of the HV side relay current elements. Referring to Figure $6 \mathrm{~b}$ and LV MCT Ratio, the injection of balanced three phase nominal LV secondary current $(0.58 \mathrm{~A})$ into corresponding relay current elements with no current injection into HV side relay current elements, the current equal to $1 \mathrm{~A}$ flows in secondary of the LV MCT, resulting in flow of $\mathrm{I}_{\text {diff }}=1$ pu using Equation (5) and $\mathrm{I}_{\text {bias }}=0.5$ pu using Equation (6). In Figure 6b, the clockwise phase shift of three phases is shown, where 6, 10, and 2 correspond to $-180^{\circ},-300^{\circ}$, and $60^{\circ}$. Tables 5 and 6 record the measurement results of the LV side relay current elements. 


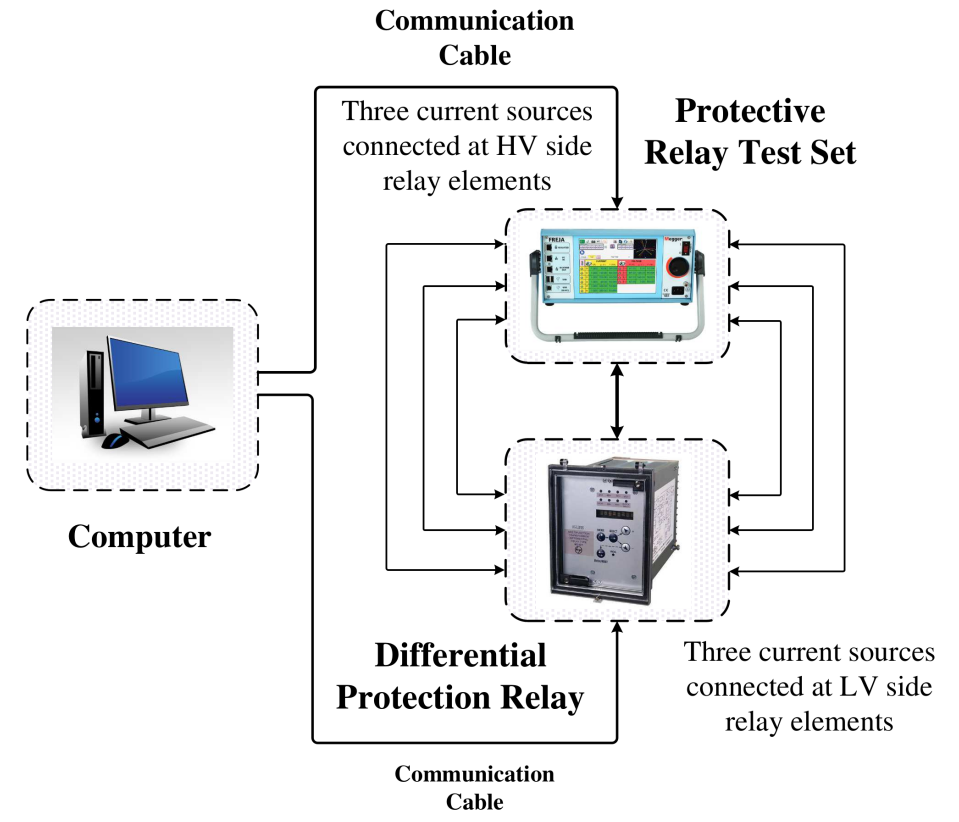

(a)

\section{Differential Relay}

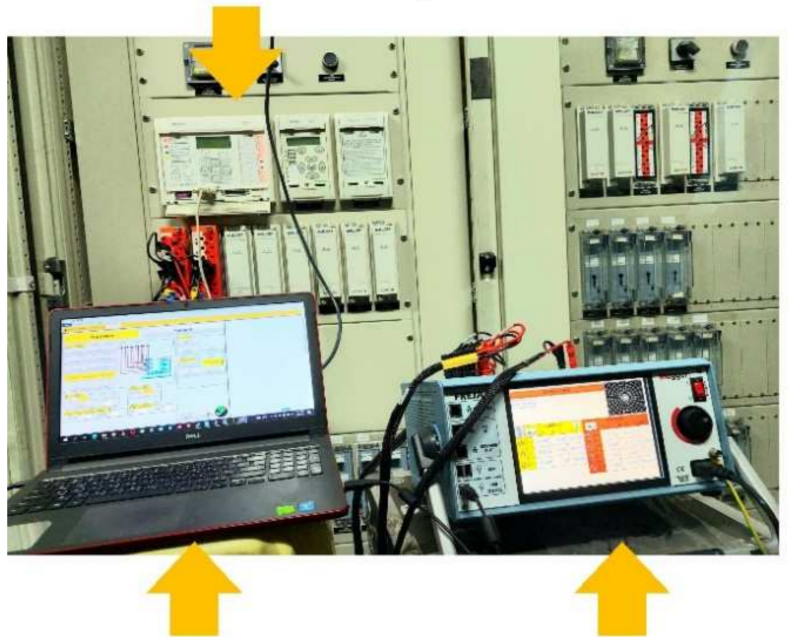

Computer

\section{Universal Relay Test Set}

Figure 5. Test bench with differential relay, test set, and computer: (a) schematic diagram, (b) pictorial view of hardware setup.

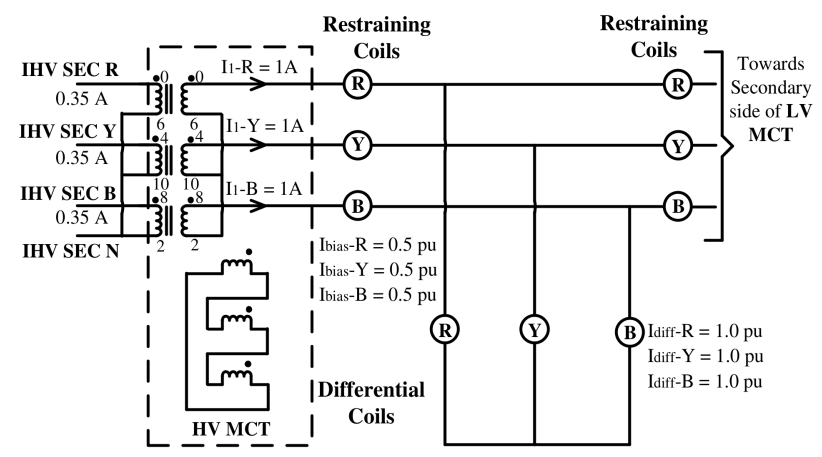

(a)

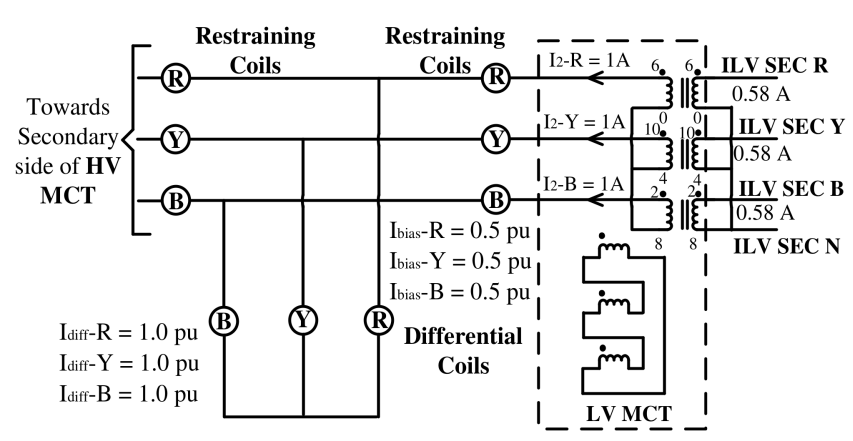

(b)

Figure 6. Three phase balanced current injection and resulting differential and bias currents in per unit (pu) for: (a) HV nominal secondary and (b) LV nominal secondary.

Table 5. Primary current observed by relay for different percentage loading of: (A) transformer HV side in terms of HV secondary current and (B) transformer LV side in terms of LV secondary current.

\begin{tabular}{ccccccccccc}
\hline & \multicolumn{4}{c}{ (A) Transformer HV Side } & \multicolumn{5}{c}{ (B) Transformer LV Side } \\
\cline { 2 - 10 } $\begin{array}{c}\text { Percentage } \\
\text { Loading }\end{array}$ & $\begin{array}{c}\text { HV Sec. } \\
\text { Current (A) }\end{array}$ & $\begin{array}{c}\text { Calc. HV } \\
\text { Primary } \\
\text { Current (A) }\end{array}$ & Obs. HV Primary (A) & $\begin{array}{c}\text { LV Sec. } \\
\text { Current (A) }\end{array}$ & $\begin{array}{c}\text { Calc. } \\
\text { LV Primary } \\
\text { Current (A) }\end{array}$ & Obs. LV Primary (A) \\
\hline $20 \%$ & 0.07 & 84 & 84.4 & 84.3 & 84.7 & 0.116 & 139.92 & 140.8 & 140.5 & 141 \\
$40 \%$ & 0.14 & 168 & 169.7 & 168.5 & 169.1 & 0.2332 & 279.84 & 280.1 & 280.7 & 281.3 \\
$60 \%$ & 0.21 & 252 & 252.6 & 254.1 & 253.1 & 0.3498 & 419.76 & 421 & 421.8 & 421.1 \\
$80 \%$ & 0.28 & 336 & 338.1 & 340.2 & 339.8 & 0.4664 & 559.68 & 564 & 564.4 & 564.3 \\
$100 \%$ & 0.35 & 420 & 421.9 & 424.3 & 422.2 & 0.583 & 699.6 & 707.9 & 706.7 & 706.3 \\
\hline
\end{tabular}


Table 6. Differential and bias current measured by relay for different percentage loading of: (A) transformer HV side and (B) transformer LV side.

\begin{tabular}{|c|c|c|c|c|c|c|c|c|}
\hline \multirow{3}{*}{$\begin{array}{l}\text { Percentage } \\
\text { Loading }\end{array}$} & \multicolumn{4}{|c|}{ (A) Transformer HV Side } & \multicolumn{4}{|c|}{ (B) Transformer LV Side } \\
\hline & \multicolumn{2}{|c|}{ Differential Current (pu) } & \multicolumn{2}{|c|}{ Bias Current (pu) } & \multicolumn{2}{|c|}{ Differential Current (pu) } & \multicolumn{2}{|c|}{ Bias Current (pu) } \\
\hline & Calc. & Obs. (Avg) & Calc & Obs. & Calc. & Obs. (Avg) & Calc. & Obs. \\
\hline $20 \%$ & 0.2 & 0.201 & 0.1 & 0.101 & 0.2 & 0.202 & 0.1 & 0.102 \\
\hline $40 \%$ & 0.4 & 0.406 & 0.2 & 0.202 & 0.4 & 0.404 & 0.2 & 0.202 \\
\hline $60 \%$ & 0.6 & 0.608 & 0.3 & 0.303 & 0.6 & 0.603 & 0.3 & 0.302 \\
\hline $80 \%$ & 0.8 & 0.811 & 0.4 & 0.405 & 0.8 & 0.809 & 0.4 & 0.403 \\
\hline $100 \%$ & 1 & 1.01 & 0.5 & 0.505 & 1 & 1.02 & 0.5 & 0.506 \\
\hline
\end{tabular}

\subsection{Pickup Test}

A pickup test is performed to check the setting $\mathrm{I}_{\mathrm{S} 1}$ in differential relay and conducted separately from HV side and LV side relay elements. From Figure 6a, the pickup computes the minimum differential current that initiate relay tripping. For pickup test, Equations (8) and (9) compute the 3-phase HV side and LV side secondary currents related the pickup setting Is1 [5]. By injecting the secondary current (Equation (8)) to the HV side while keeping LV side to zero, the relay should pick up and trip as per setting. Similarly, if the current (Equation (9)) is injected to the LV side relay elements, the relay should pick up and tripping as per setting while keeping HV side to zero. The $H V_{\text {nom sec }}$ and $L V_{\text {nom sec }}$ are the nominal secondary CT currents for HV and LV sides.

$$
\begin{aligned}
3-\text { Phase Pickup current for } H V \text { side } & =I_{S 1} \times H V_{\text {nom sec }} \\
3-\text { Phase Pickup current for } L V \text { side } & =I_{S 1} \times L V_{\text {nom sec }}
\end{aligned}
$$

During testing, the gradual current increase is observed till relay pick up threshold and compared with the calculated value. Moreover, the respective current is gradually decreased until the relay drops off. Equations (10) and (11) are used for single phase pickup current injection calculation for HV and LV sides, respectively, while Equations (12) and (13) are used for two phase pickup current injection calculation for HV and LV sides, respectively [5].

$$
\begin{gathered}
1 \text { Ph. Pickup current for } \mathrm{HV} \text { side }=\mathrm{I}_{\mathrm{S} 1} \times \mathrm{HV}_{\text {nom sec }} \times \mathrm{MF} \\
1 \text { Ph. Pickup current for } \mathrm{LV} \text { side }=\mathrm{I}_{\mathrm{S} 1} \times \mathrm{LV}_{\text {nom sec }} \times \mathrm{MF} \\
2 \text { Ph. Pickup current for } \mathrm{HV} \text { side }=\mathrm{I}_{\mathrm{S} 1} \times \mathrm{HV}_{\text {nom sec }} \\
2 \text { Ph. Pickup current for } \mathrm{LV} \text { side }=\mathrm{I}_{\mathrm{S} 1} \times \mathrm{LV}_{\text {nom sec }} \times \mathrm{MF}
\end{gathered}
$$

where MF is the multiplying factor where applicable that depends on the MCT configuration and zero sequence current filtering (enabled or disabled) status. For Equations (10)-(13), the $M F$ is computed using sequence current $\left(\mathrm{I}_{0}, \mathrm{I}_{1}\right.$, and $\left.\mathrm{I}_{2}\right)$ given in Ref. [5]. Using [5], it is apparent that $M F$ value in Equations (10) and (11) is $\frac{3}{2}$, while in Equation (13) the $M F$ is 1. Table 7 shows the single, double, and three phase testing results where the acceptable range for pick-up observed is computed using the following range formula given in [24] as $0.9 \times$ Pickup Calc. $-1.1 \times$ Pickup Calc, and for drop-off observed, the range I defined as $0.9 \times$ Pickup Calc. to $1.0 \times$ Pickup Calc. Table 7 illustrates that for both HV and LV sides, all the pickup observed, and drop-off observed values for single, double, and three phase pickup tests are within the aforementioned ranges. 
Table 7. Single, double, and three phase pickup and drop-off test of differential relay.

\begin{tabular}{|c|c|c|c|c|c|c|}
\hline \multirow[b]{2}{*}{ Sr. No. } & \multicolumn{3}{|c|}{ HV Side } & \multicolumn{3}{|c|}{ LV Side } \\
\hline & $\begin{array}{c}\text { Pickup } \\
\text { Calc. (A) }\end{array}$ & $\begin{array}{c}\text { Pickup } \\
\text { Obs. (A) }\end{array}$ & $\begin{array}{l}\text { Drop off } \\
\text { Obs. (A) }\end{array}$ & $\begin{array}{c}\text { Pickup } \\
\text { Calc. (A) }\end{array}$ & $\begin{array}{c}\text { Pickup } \\
\text { Obs. (A) }\end{array}$ & $\begin{array}{l}\text { Drop off } \\
\text { Obs. (A) }\end{array}$ \\
\hline \multicolumn{7}{|c|}{ Single Phase Pickup Test } \\
\hline $\mathrm{R}$ & 0.078 & 0.078 & 0.073 & 0.131 & 0.133 & 0.123 \\
\hline $\mathrm{Y}$ & 0.078 & 0.079 & 0.074 & 0.131 & 0.131 & 0.122 \\
\hline B & 0.078 & 0.08 & 0.072 & 0.131 & 0.130 & 0.124 \\
\hline \multicolumn{7}{|c|}{ Double Phase Pickup Test } \\
\hline RY & 0.0525 & 0.052 & 0.048 & 0.0874 & 0.087 & 0.082 \\
\hline YB & 0.0525 & 0.051 & 0.047 & 0.0874 & 0.087 & 0.081 \\
\hline $\mathrm{BR}$ & 0.0525 & 0.051 & 0.048 & 0.0874 & 0.086 & 0.081 \\
\hline \multicolumn{7}{|c|}{ Three Phase Pickup Test } \\
\hline RYB & 0.0525 & 0.052 & 0.048 & 0.0874 & 0.088 & 0.082 \\
\hline
\end{tabular}

Figure 7a shows the waveform for HV side Blue phase (IC_1) observed pickup current $(0.08 \mathrm{~A}))$. Before the injection of observed pickup current, transformer rated currents are applied as pre-fault to the differential relay. The pre-fault current values read by relay are 419.6 A (RMS) for primary side and 698.6 A (RMS) for secondary side. The fault current in IC_1 measured by relay is $105.5 \mathrm{~A}(R M S)$, secondary current $\left.=\frac{105.5}{1200}=0.087 \mathrm{~A}\right)$. The injected secondary current generates $I_{\text {diff }}=0.149$ according to graph which is very close to the pickup setting of relay $(0.15 \mathrm{pu})$.

Figure $7 \mathrm{~b}$ shows the waveform for LV side yellow phase (IB_2) observed pickup current $(0.131 \mathrm{~A})$. Before the injection of observed pickup current, transformer rated currents are applied as pre-fault to differential relay. The pre-fault current values read by relay are $421.9 \mathrm{~A}(R M S)$ for primary side and $693.9 \mathrm{~A}(R M S)$ for secondary side. The fault current in IB_2 measured by relay is $168.7 \mathrm{~A}(R M S)$, secondary current $\left.=\frac{168.7}{1200}=0.140 \mathrm{~A}\right)$. The injected secondary current generates $I_{\text {diff }}=0.149$ as per graph, which is very close to the pickup setting of relay $(0.15 \mathrm{pu})$.

Figure 7c shows the waveform for HV side three phase (IA_1, IB_1, IC_1) observed pickup current $(0.052 \mathrm{~A})$. Before the injection of observed pickup current, transformer rated currents are applied as pre-fault to differential relay. The pre-fault current values read by relay are 417.3 $\mathrm{A}(R M S)$ for primary side and 696.2 $\mathrm{A}(R M S)$ for secondary side. The fault currents $I A \_1, I B \_1, I C \_1$ measured by relay are $69.78 \mathrm{~A}(R M S)$, secondary current $=\frac{69.78}{1200}=0.058$ A. The injected secondary current generates $I_{\text {diff }}=0.149$ as per graph, which is close to pickup setting of relay $(0.15 \mathrm{pu})$.

Figure $7 \mathrm{~d}$ shows the waveform for $\mathrm{LV}$ side three phase (IA_2, IB_2, IC_2) observed pickup current $(0.088 \mathrm{~A})$. Before the injection of observed pickup current, transformer rated currents are applied as pre-fault to differential relay. The pre-fault current values read by relay are $414.9 \mathrm{~A}(R M S)$ for primary side and $698.5 \mathrm{~A}(R M S)$ for secondary side. The fault current $I A \_2, I B \_2$, IC_2 measured by relay is $103.15 \mathrm{~A}(R M S)$, secondary current $\left.=\frac{103.15}{1200}=0.085 \mathrm{~A}\right)$. The injected secondary current generates $I_{\text {diff }}=0.151$ as per graph, which is close to pickup setting of relay $(0.15 \mathrm{pu})$.

\subsection{Trip Time Test}

The trip time test is performed to measure the time from inception of fault till relay trips. The recommendation is to test trip time at 5.0 $\times$ HV Pickup Calc. [24]. The results of trip time test are recorded using three-phase current injection into HV side relay current elements $5.0 \times \mathrm{HV}$ Pickup Calc., which is $0.2625 \mathrm{~A}$. The acceptable range is $30-35 \mathrm{~ms}$, while observed is $27 \mathrm{~ms}$. The simulation and analysis performed in Section 6.9 explicitly discuss the trip time test of numerical differential relay. 


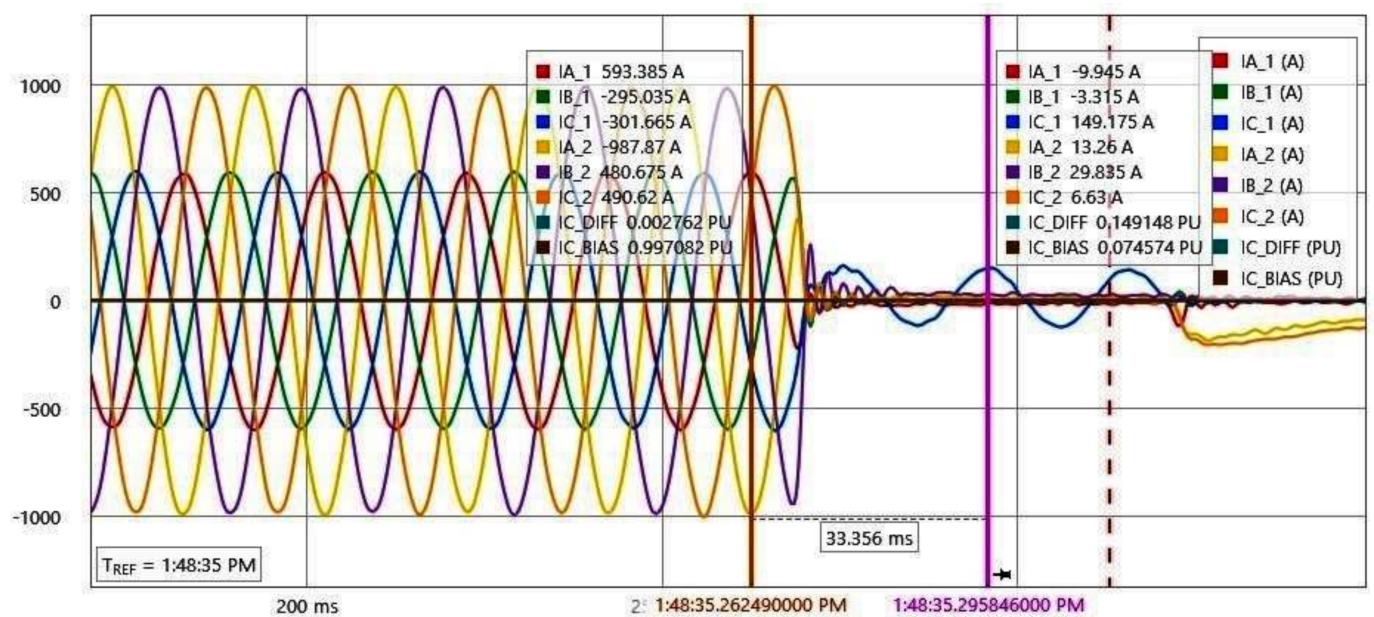

(a)

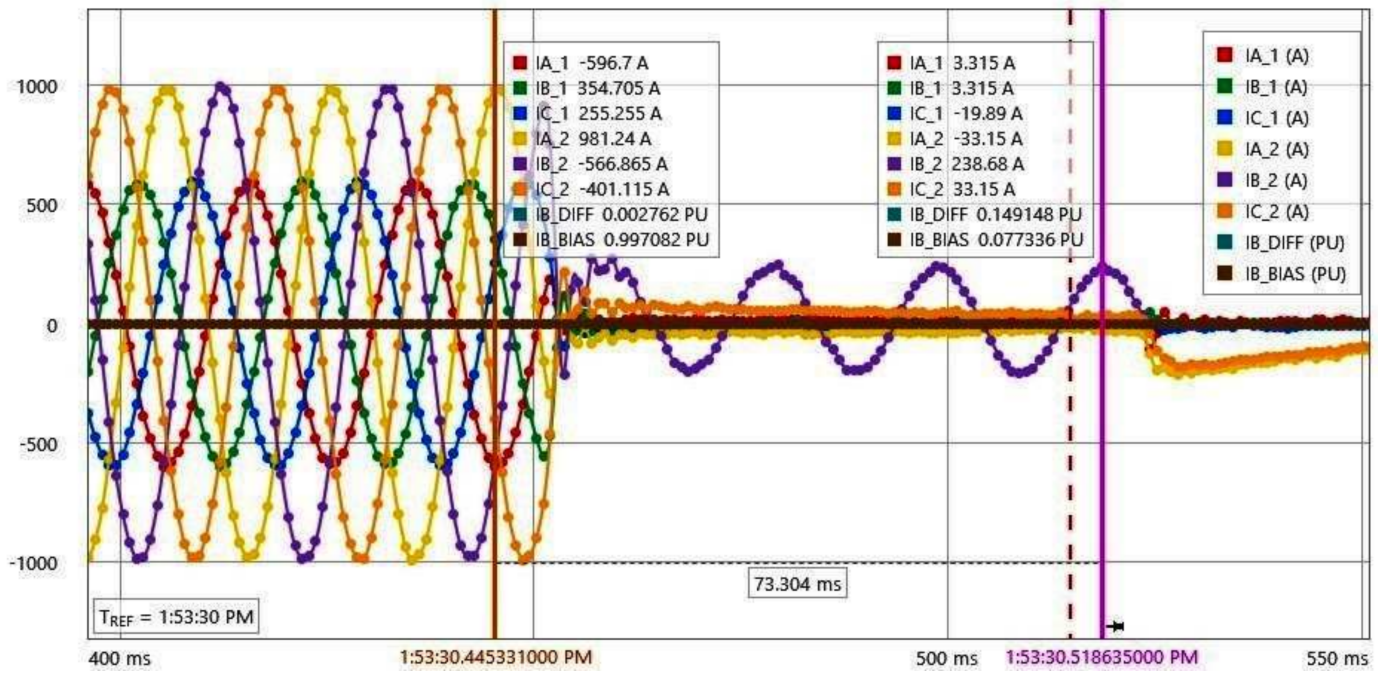

(b)

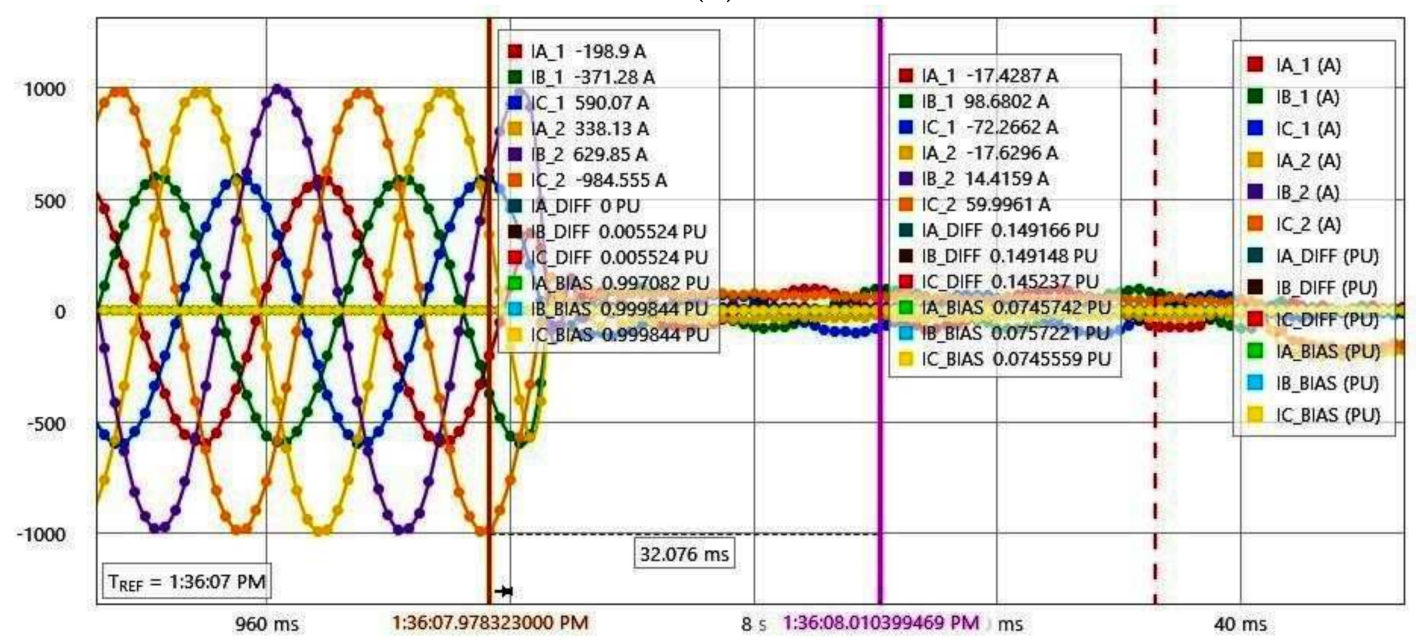

(c)

Figure 7. Cont. 


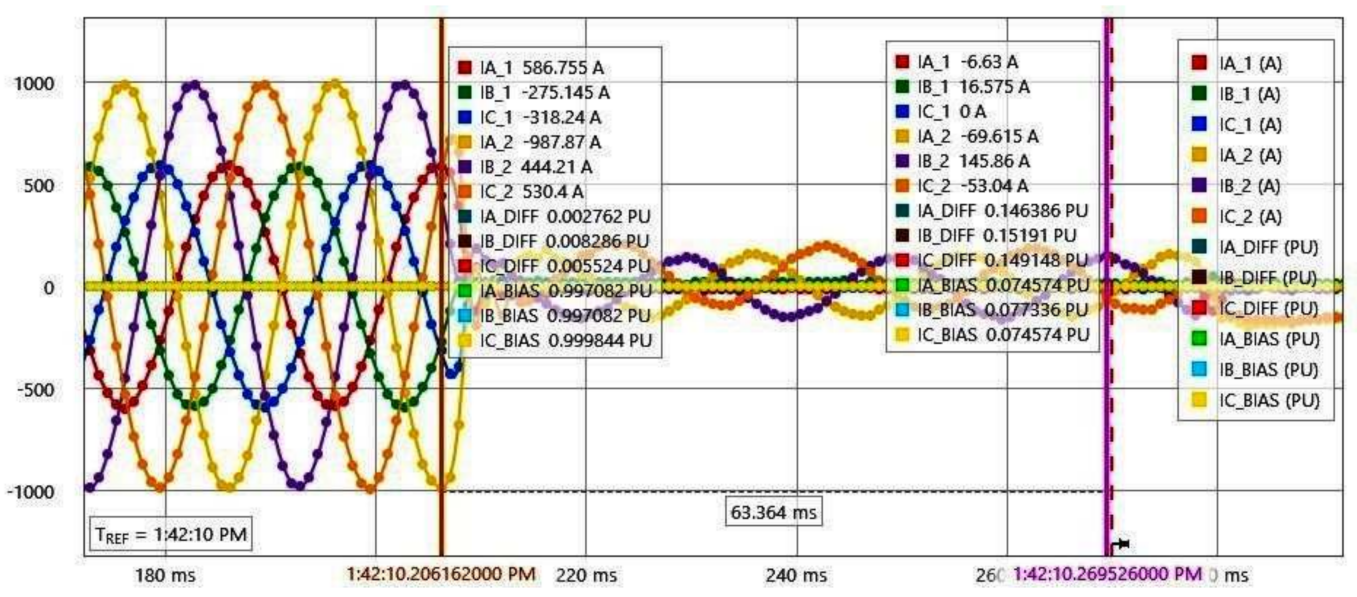

(d)

Figure 7. Pickup and drop-off test of differential relay: (a) HV side blue phase, (b) LV side yellow phase, (c) HV side three phase, (d) LV side three phase.

\subsection{Stability Test}

During through fault, the relay must remain stable and must not initiate tripping. Ideally, the bias current increases but the differential current remains low (near to zero). Practically, some differential current may be observed (due to CT saturation); however, the relay remains stable due to bias characteristics. The stability test is performed by simulating the condition for through fault. The condition can be simulated by simultaneously applying nominal HV and LV secondary currents at respective relay current elements. Table 8 presents the differential and bias currents measurements by the relay when 5 times of balanced HV and LV nominal secondary currents are applied at relay terminals.

\subsection{Bias Test}

Referring to the bias characteristics shown in Figure 4, testing of bias characteristics includes testing all three slopes. For each slope, two points are considered on the graph, near to the boundary of trip and restrain region. The current injections that correspond to the selected points are injected in the relay and its behavior is recorded. Figure 8 shows the points selected on Figure 4. Using Equations (5) and (6), the currents $I_{1}$ and $I_{2}$ shown in Figure $6 a, b$, respectively, are calculated for each point selected on Figure 8 . Moreover, the $I_{H V ~ s e c}$ and $I_{L V ~ s e c}$ corresponding to $I_{1}$ and $I_{2}$, respectively, are calculated in amperes. The 3phase $I_{H V \text { sec }}$ and $I_{L V \text { sec }}$ with angles shown in the stability test are applied simultaneously to the corresponding relay elements. The behavior of relay (Trip/No Trip) is recorded, and $I_{\text {diff }}$ and $I_{\text {bias }}$ measured by relay is compared with the computed value of selected point. To illustrate this phenomenon, recorded results are shown in Table 9.

Figure 9a shows the waveform of currents corresponding to Point ' $\mathrm{B}$ ' mentioned in Table 9. Before the injection of currents corresponding to Point ' $\mathrm{B}$ ', transformer rated currents are applied as pre-fault to differential relay. The pre-fault current values read by relay are 414.9 A (RMS) for primary side and 698.6 A (RMS) for secondary side. The injected three phase $\mathrm{HV}$ and LV fault currents into relay result into $I_{\text {diff }}=0.18 \mathrm{pu}$ and $I_{\text {bias }}=0.40 \mathrm{pu}$. The observed $I_{\text {diff }}$ and $I_{\text {bias }}$ from relay are in accordance with the $I_{\text {diff }}$ and $I_{\text {bias }}$ of Point 'B' as apparent from Figure 8.

Figure $9 \mathrm{~b}$ shows the waveform of currents corresponding to Point ' $\mathrm{F}^{\prime}$ mentioned in Table 9. The injected three phase HV and LV fault currents into relay result into $I_{\text {diff }}=1.26$ pu and $I_{\text {bias }}=3.0 \mathrm{pu}$. The observed $I_{\text {diff }}$ and $I_{\text {bias }}$ from relay are in accordance with the $I_{\text {diff }}$ and $I_{\text {bias }}$ of Point ' $\mathrm{F}$ ' as apparent from Figure 8. 
Table 8. Stability test results when 5 times of nominal HV secondary and LV secondary currents is applied.

\begin{tabular}{|c|c|c|c|c|c|}
\hline $\begin{array}{l}\text { Current Applied at } \\
\text { HV Side Relay } \\
\text { Elements }\end{array}$ & $\begin{array}{l}\text { Current Applied at } \\
\text { LV Side Relay } \\
\text { Elements }\end{array}$ & $I_{\text {diff }}$ Calc. (pu) & $I_{\text {bias }}$ Calc. (pu) & $I_{\text {diff }}$ Obs. (pu) & $I_{\text {bias }}$ Obs. (pu) \\
\hline $1.75\left\llcorner 0^{\circ}\right.$ & $2.915\left\llcorner 180^{\circ}\right.$ & & & & \\
\hline $1.75\left\llcorner 240^{\circ}\right.$ & $2.915\left\llcorner 60^{\circ}\right.$ & 0.0 & 5.0 & 0.012 & 5.04 \\
\hline $1.75\left\llcorner 120^{\circ}\right.$ & $2.915\left\llcorner 300^{\circ}\right.$ & & & & \\
\hline
\end{tabular}

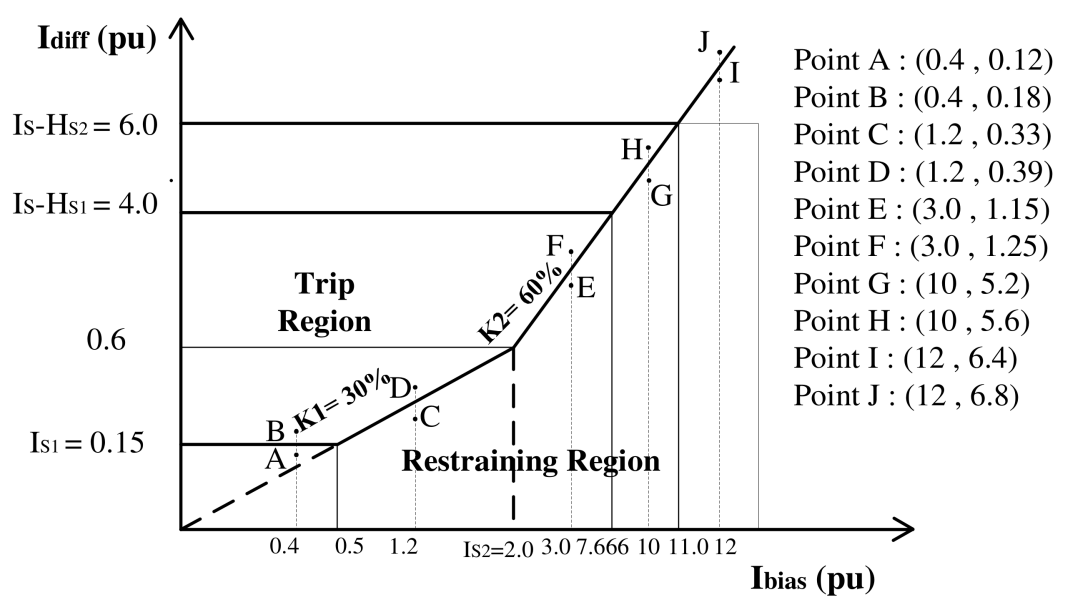

Figure 8. Differential characteristics or bias characteristics with selected points.

\subsection{The 2nd and 5th Harmonic Restraint Test}

In-rush current and over fluxing of transformers results in increased 2nd harmonic and 5th harmonic current components, respectively. Once the harmonic contents are detected as per threshold setting, the relay's operation is restrained. The restraining of relay operation is tested by simultaneously injecting fundamental component of current (must be higher than $I_{\text {diff }}$ and kept constant during test), and 2nd or 5th harmonic component into relay current element. By increasing the 2nd or 5th harmonic component, the percentage setting is verified from Table 4 at address 31.29 and 31.34, respectively. Results are given in Table 10.

\subsection{High Stage 1 and High Stage 2 Test}

To verify high stage 1 tripping, the differential protection must remain unblocked once the condition $I_{\text {diff }}>I_{S}-H_{S 1}$ is fulfilled. The testing is performed per phase for HV side relay elements only. The results of high stage 1 test for setting given in Table 4 are recorded in Table 11. Moreover, the settings ' $I_{S}-H_{S 1}$ ' and ' $I_{S}-H_{S 2}$ ' are tested by testing points G, H and I, J, respectively, as shown in Figure 8. Table 12 records the test results for points $\mathrm{G}, \mathrm{H}, \mathrm{I}$, and J.

Figure 10a shows the waveform of currents corresponding to Point ' $\mathrm{H}$ ' mentioned in Table 12. The injected three phase HV and LV fault currents into relay result into $I_{\text {diff }}=5.6 \mathrm{pu} \& I_{\text {bias }}=10.0 \mathrm{pu}$. The observed $I_{\text {diff }}$ and $I_{\text {bias }}$ from relay are in accordance with the $I_{\text {diff }}$ and $I_{\text {bias }}$ of Point ' $\mathrm{H}$ ' as apparent from Figure 8.

Figure $10 \mathrm{~b}$ shows the waveform of currents corresponding to Point ' $\mathrm{I}$ ' mentioned in Table 12. The injected three phase HV and LV fault currents into relay result into $I_{\text {diff }}=6.4 \mathrm{pu} \& I_{\text {bias }}=12.0 \mathrm{pu}$. The observed $I_{\text {diff }}$ and $I_{\text {bias }}$ from relay are in accordance with the $I_{\text {diff }}$ and $I_{\text {bias }}$ of Point ' $I$ ' as apparent from Figure 8. 
Table 9. Test results of bias characteristics for points selected in Figure 11a.

\begin{tabular}{|c|c|c|c|c|c|c|c|}
\hline Point & $I_{1}(\mathrm{pu})$ & $I_{2}(\mathrm{pu})$ & $I_{H V \text { sec }}(\mathrm{A})$ & $I_{L V \text { sec }}(\mathrm{A})$ & $I_{\text {diff }}$ obs. (pu) & $I_{\text {bias }}$ obs. (pu) & Trip/No Trip \\
\hline A & 0.46 & 0.34 & 0.161 & 0.198 & 0.12 & 0.404 & No trip \\
\hline B & 0.49 & 0.31 & 0.171 & 0.180 & 0.18 & 0.404 & Trip \\
\hline $\mathrm{C}$ & 1.36 & 1.03 & 0.478 & 0.603 & 0.33 & 1.213 & No trip \\
\hline $\mathrm{D}$ & 1.39 & 1.00 & 0.488 & 0.586 & 0.39 & 1.213 & Trip \\
\hline $\mathrm{E}$ & 3.57 & 2.42 & 1.251 & 1.413 & 1.16 & 3.028 & No trip \\
\hline F & 3.62 & 2.37 & 1.269 & 1.384 & 1.26 & 3.031 & Trip \\
\hline
\end{tabular}

Table 10. Results of 2nd and 5th harmonic restraint test.

\begin{tabular}{cccccc}
\hline $\begin{array}{c}\text { Relay Current } \\
\text { Element }\end{array}$ & $\begin{array}{c}\text { Current Injected (A) } \\
\mathbf{5 0 ~ H z}\end{array}$ & $\begin{array}{c}\text { 2nd Harm. Block } \\
\text { Th. Setting (\%) }\end{array}$ & $\begin{array}{c}\text { 2nd Harm. Block } \\
\text { Obs.\% }\end{array}$ & $\begin{array}{c}\text { 5th Harm. Block } \\
\text { Th. Setting\% }\end{array}$ & $\begin{array}{c}\text { 5th Harm. Block } \\
\text { Obs.\% }\end{array}$ \\
\hline$I_{H V \sec R}$ & 0.5 & 15 & 14.6 & 40 & 41.1 \\
$I_{H V \sec } Y$ & 0.5 & 15 & 14.6 & 40 & 40.9 \\
$I_{H V \sec B}$ & 0.5 & 15 & 14.2 & 40 & 40.4 \\
\hline
\end{tabular}

Table 11. Test results of effect of setting ' $I_{S}-H_{S 1}$ ' and 2nd harmonic component on differential protection status.

\begin{tabular}{ccccc}
\hline HV Side Relay Element & $\begin{array}{c}\boldsymbol{I}_{\text {diff }} \\
\text { (per Unit) }\end{array}$ & $\begin{array}{c}\text { Current Applied (A) } \\
\mathbf{5 0 ~} \mathbf{~ H z})\end{array}$ & 2nd Harmonic Current & Differential Protection Status \\
\hline \multirow{2}{*}{ Red } & 3.6 & 1.9 & $14.7 \%$ & Blocked \\
& 4.10 & 2.16 & $1.9 .7 \%$ & Unblocked \\
\hline \multirow{2}{*}{ Yellow } & 3.6 & 2.16 & $\geq 14.8 \%$ & Blocked \\
& 4.10 & 1.9 & $14.8 \%$ & Unblocked \\
\hline \multirow{2}{*}{ Blue } & 3.6 & 2.16 & $\geq 14.8 \%$ & Blocked \\
& 4.10 & Unblocked & \\
\hline
\end{tabular}

Table 12. Test results of bias characteristics for points selected in accordance with setting ' $I_{S}-H_{S 1}{ }^{\prime}$ and ' $I_{S}-H_{S 2}$ ' in Figure 11a.

\begin{tabular}{|c|c|c|c|c|c|c|c|}
\hline Point & $I_{1}(\mathrm{pu})$ & $I_{2}(\mathrm{pu})$ & $I_{H V ~ s e c}(\mathrm{~A})$ & $I_{L V \text { sec }}(\mathrm{A})$ & $I_{\text {diff }}$ Obs. (pu) & $I_{\text {bias }}$ Obs. (pu) & Trip/No Trip \\
\hline G & 12.6 & 7.4 & 4.41 & 4.31 & 5.23 & 10 & No Trip \\
\hline $\mathrm{H}$ & 12.8 & 7.2 & 4.48 & 4.19 & 5.63 & 10.0 & Trip \\
\hline I & 15.2 & 8.8 & 5.32 & 5.13 & 6.44 & 12 & Trip \\
\hline $\mathrm{J}$ & 15.4 & 8.6 & 5.39 & 5.01 & 6.84 & 12 & Trip \\
\hline
\end{tabular}

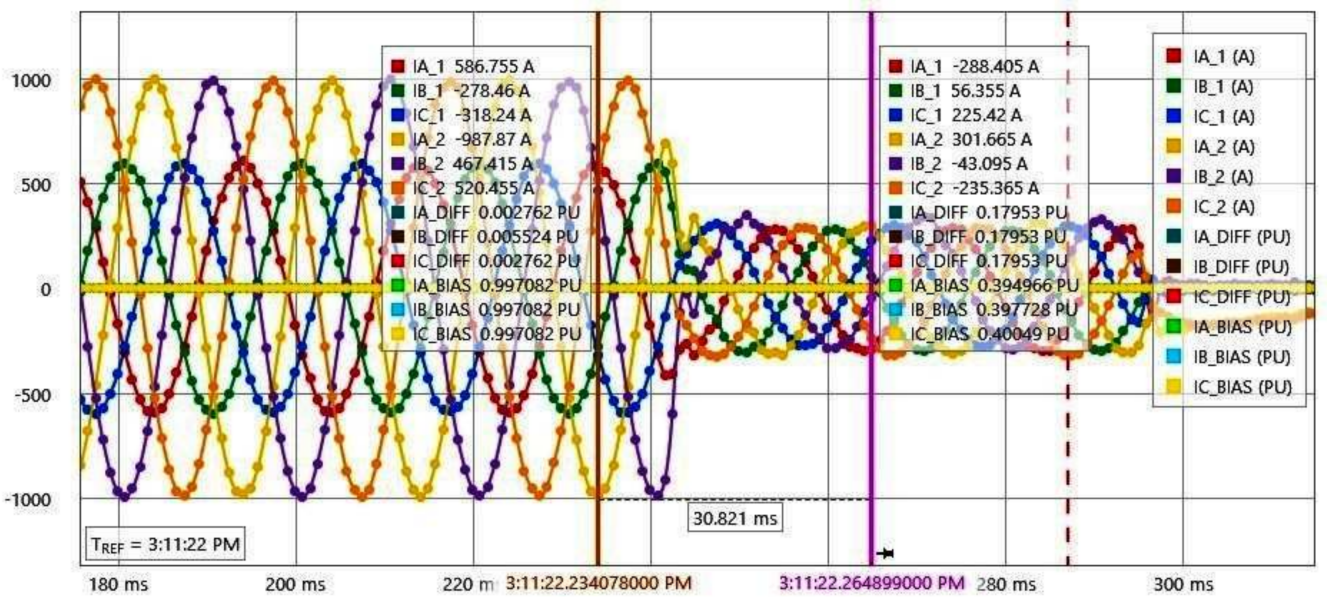

(a)

Figure 9. Cont. 


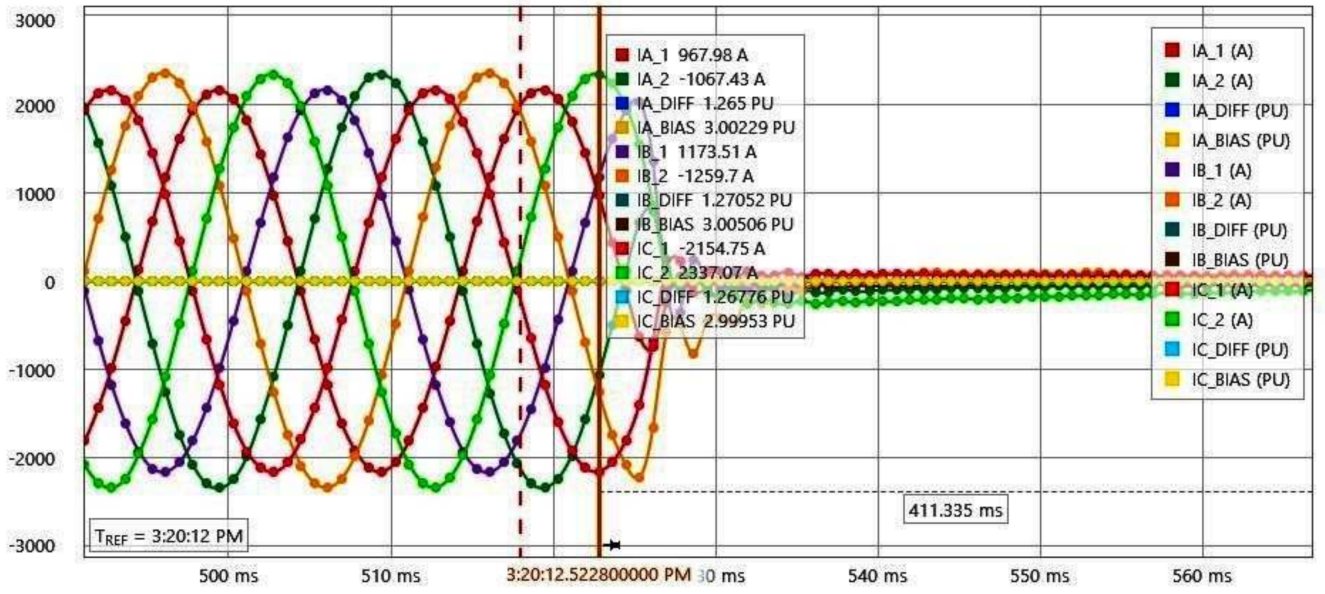

(b)

Figure 9. Waveforms of bias characteristics for points selected in Figure 11a: (a) point B, (b) point F.

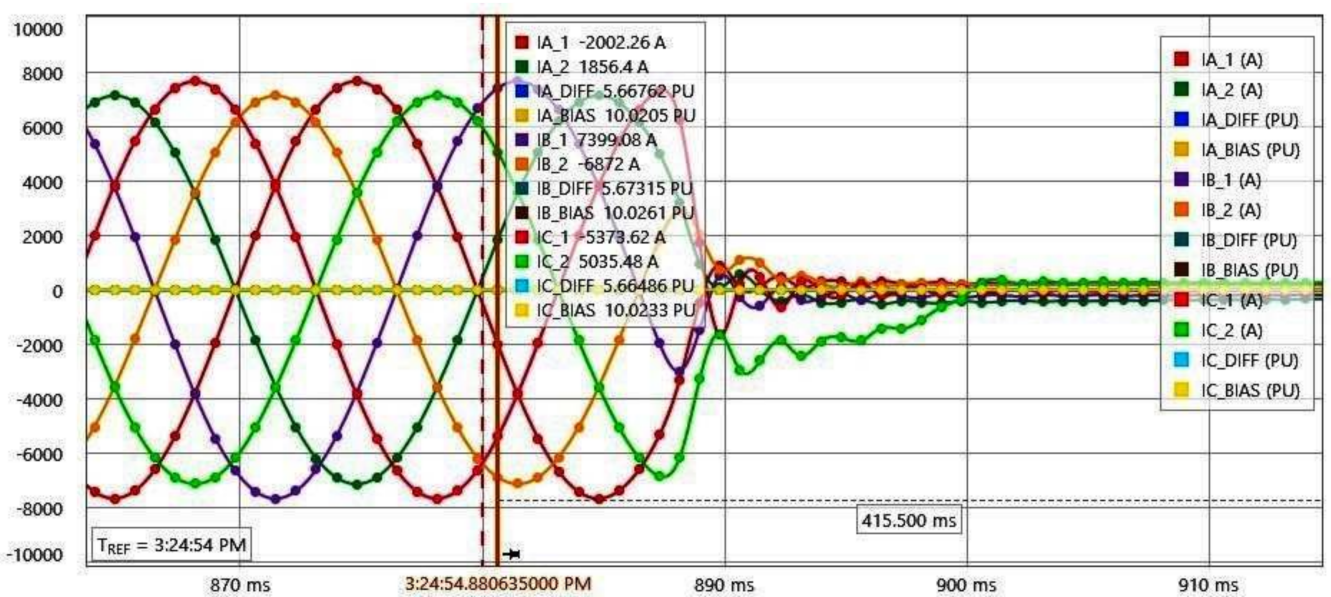

(a)

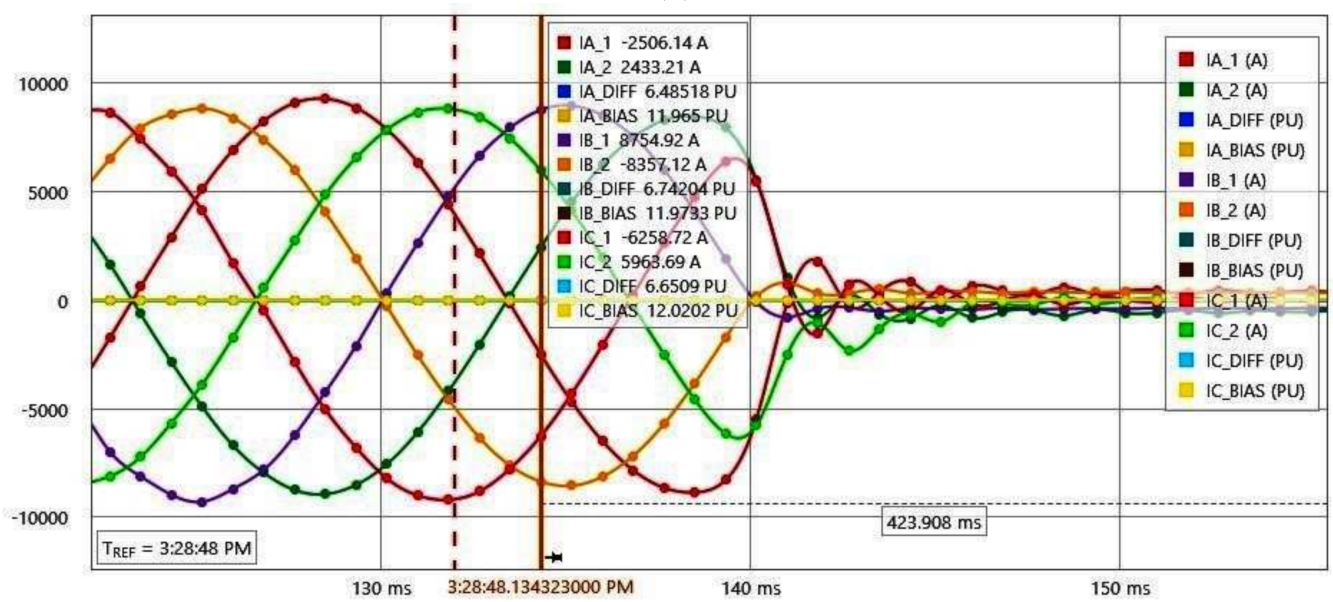

(b)

Figure 10. Waveforms of bias characteristics for points selected in accordance with setting ' $I_{S}-H_{S 1}$ ' and ' $I_{S}-H_{S 2}$ ' in Figure 11a: (a) point $H$, (b) point I.

\subsection{Simulation Results and Discussion}

In addition to testing, the numerical relays also generate time stamped waveforms and measurements as standard format COMTRADE [27]. Such waveform can provide important insight into pre-fault conditions, fault inception, post-fault conditions, and behavior of relay under real-time fault situations. Few current waveforms from COMTRADE files 
generated by relay for trip time test and bias characteristics test (point D) are displayed for discussion. Current waveforms for trip time test (fault current applied for extended time regardless of relay trip) and bias characteristic test at point $\mathrm{D}$ (fault current applied with nominal currents as pre-fault) in Figure 8 are presented in Figures $8 \mathrm{a}$ and 11b, respectively. The waveforms are plotted through SEL SynchroWAVE Event [28]. Figure 11a shows relay reads Red Phase Primary Current (IA_1_1.sec) as 307A (RMS), which is approximately equal to $315 A$, as per discussed calculations. Similarly, Red Phase Differential Current (IA_DIFF) is observed as $I_{\text {diff }}=0.7540 \mathrm{pu}$ and Red Phase Bias Current (IA_BIAS) is observed as $I_{\text {bias }}=0.3783$ pu. Observed values of Red Phase Differential Current (IA_DIFF) and Red Phase Bias Current (IA_BIAS) are as per calculations discussed. The calculated values of Red Phase Differential Current and Red Phase Bias Current being $I_{\text {diff }}=0.75$ pu and $I_{\text {bias }}=0.375 \mathrm{pu}$, respectively. Figure $11 \mathrm{~b}$ shows transformer red phase currents calculated by relay (IA_1_1.sec corresponds to HV side red phase current, IA_2_1.sec corresponds to LV side red phase current, IA_DIFF corresponds to red phase differential current, and IA_BIAS corresponds to red phase bias current) when point D in Figure 8 is simulated with nominal currents as pre-fault. The brown and purple color cursor shows HV side, LV side, $I_{\text {diff }}$ and $I_{\text {bias }}$ currents of red phase at pre-fault and fault values, respectively. Pre-Fault Red Phase Primary currents of HV side and LV side calculated by relay are 440A (RMS) and 690A (RMS), respectively. The calculated primary current values are close to actual nominal current of HV side (420A) and LV side (700A). During pre-fault, $I_{\text {diff }}$ and $I_{\text {bias }}$ currents of red phase are calculated by relay as $I_{\text {diff }}=0.008 \mathrm{pu}$ and $I_{\text {bias }}=1.010$, respectively. Pre-fault values of $I_{\text {diff }}$ and $I_{\text {bias }}$ calculated by relay are very close to actual calculated values of $I_{\text {diff }}$ and $I_{\text {bias }}$ given as $I_{\text {diff }}=0 \mathrm{pu}$ and $I_{\text {bias }}=1.0 \mathrm{pu}$. Fault values of $I_{\text {diff }}$ and $I_{\text {bias }}$ calculated by relay, shown in Figure $11 \mathrm{~b}$, are $I_{\text {diff }}=0.3949$ pu and $I_{\text {bias }}=1.2263$. Fault values of $I_{\text {diff }}$ and $I_{\text {bias }}$ calculated by relay are very close to actual calculated values of $I_{\text {diff }}$ and $I_{\text {bias }}$ for point D given as $I_{\text {diff }}=0.39 \mathrm{pu}$ and $I_{\text {bias }}=1.2$ also shown in Figure 8 .

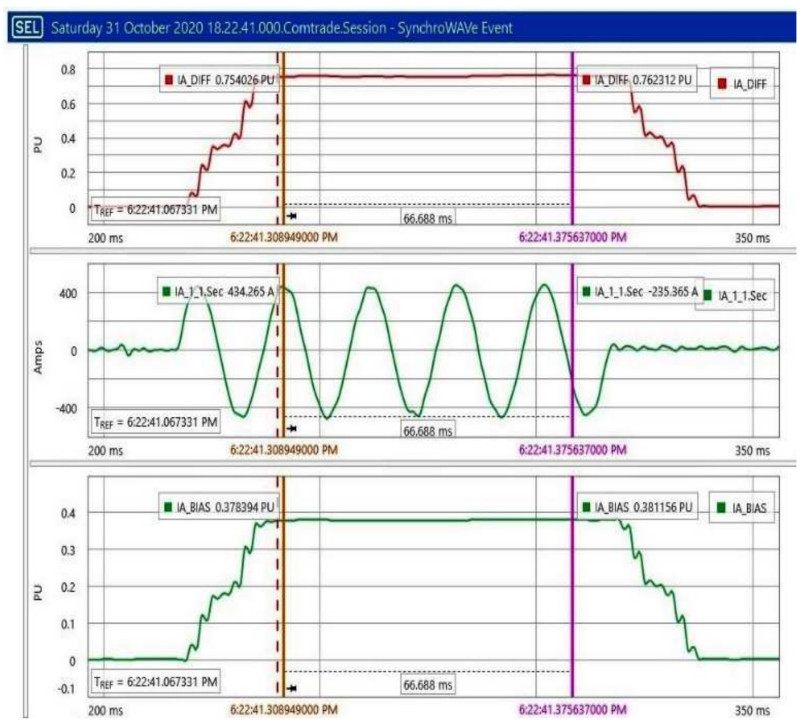

(a)

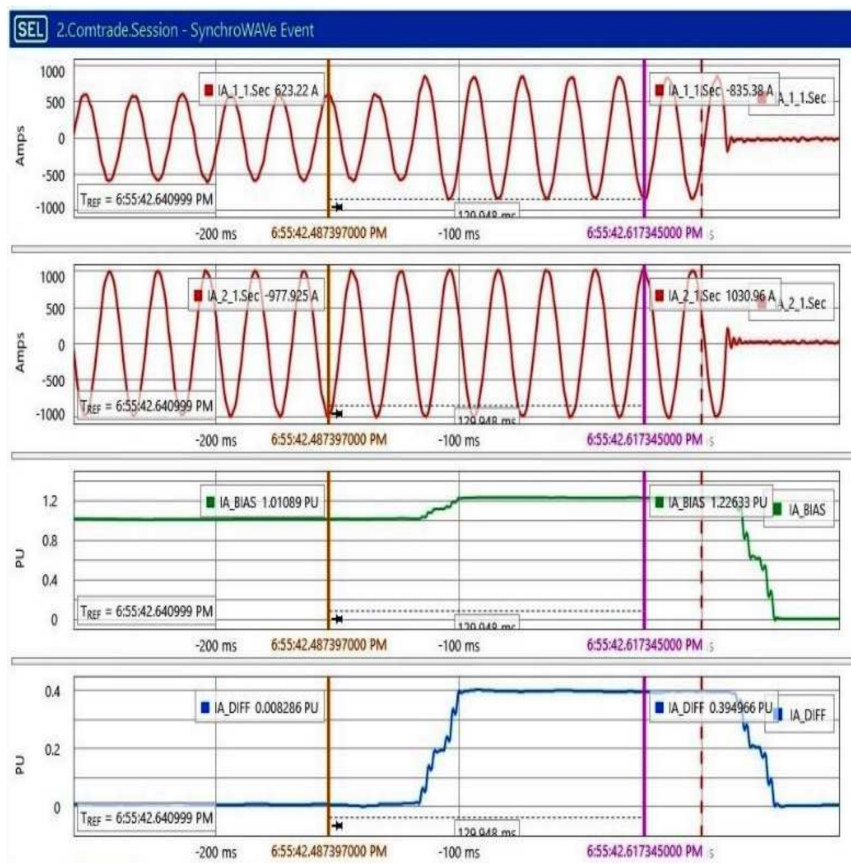

(b)

Figure 11. Waveform of: (a) Red Phase Current, $I_{\text {diff }}$ and $I_{\text {bias }}$ of red phase for fault simulated in trip time test, (b) HV and LV Red Phase Current, $I_{\text {diff }}$ and $I_{\text {bias }}$ for point D of Figure 8. 


\section{Conclusions and Future Work}

In this paper, a complete procedural guideline for the practical implementation of numerical differential relay testing procedures was prepared and composed for insight analysis of relay settings for the protection of an EHV 220/132 kV auto transformer. Moreover, based on the experimental results, a detailed technical and theoretical analysis including connection details, operating principle, and biasing characteristics was also performed. A secondary injection relay test set was used for the detailed testing of numerical differential relay. For this purpose, a "six current source secondary injection universal relay test set" was connected to the relay. Keeping in view of the prepared formal procedural guideline, the real-time implementation of relay was performed, which gives a detailed insight study that can be helpful for the research community and power system protection experts in understanding the basic principles, operation, and testing of numerical differential relays. The tests used to monitor a relay's health include measurement test, pickup test, trip-time test, stability test, bias characteristics test, 2nd and 5th harmonic restraints test, and high stage 1 and high stage 2 test. The testing results were then critically analyzed from theoretical and practical perspectives to insure the relay's satisfactory performance. Table 13 tabulates the summarized results of relay testing with the final remarks presented against each test. The testing results of the differential relay under consideration are satisfactory and indicate the sound health and appropriate functionality of relay.

Table 13. Summarized results of differential relay testing.

\begin{tabular}{|c|c|c|c|}
\hline Sr. No. & Test Performed & Observations & Remarks \\
\hline 1 & Measurement Test & Comparison of meas. and calc. values & Satisfactory \\
\hline 2 & Pickup Test & $\begin{array}{c}\text { Single, double, and three phase pickup test results lie in acceptable } \\
\text { range specified in [24] }\end{array}$ & Satisfactory \\
\hline 3 & Trip Time Test & $\begin{array}{l}\text { The observed trip time lies in acceptable range (30 to } 35 \mathrm{~ms} \text { ) } \\
\text { specified in [24] }\end{array}$ & Satisfactory \\
\hline 4 & Stability Test & Observed $I_{\text {diff }}$ and $I_{\text {bias }}$ values are comparable to calc. values & Satisfactory \\
\hline 5 & Bias Characteristics Test & $\begin{array}{l}\text { Bias characteristics test result for test points shown in Figure } 8 \text { are } \\
\text { as per respective region (trip/restrain). Additionally, the obs. } I_{\text {diff }} \\
\text { and } I_{\text {bias }} \text { currents of relay are comparable to calc. } I_{\text {diff }} \text { and } I_{\text {bias }} \\
\text { shown in Figure } 8 .\end{array}$ & Satisfactory \\
\hline 6 & $\begin{array}{l}\text { 2nd and 5th Harmonic } \\
\text { Restraint Test }\end{array}$ & $\begin{array}{l}\text { Observed 2nd and 5th harmonic restraint test results are } \\
\text { comparable to the corresponding setting thresholds }\end{array}$ & Satisfactory \\
\hline 7 & $\begin{array}{l}\text { High Stage } 1 \text { and High } \\
\text { Stage } 2 \text { Test }\end{array}$ & $\begin{array}{c}\text { High Stage } 1 \text { and } 2 \text { test results for test points shown in Figure } 8 \text { are } \\
\text { as per respective region (trip/restrain) }\end{array}$ & Satisfactory \\
\hline
\end{tabular}

If the behavior of relay deviates from the applied settings in such a way that the deviation is greater than the allowed tolerance by manufacturer and it is made sure again that the testing procedure followed is proper and comprehensive and the relay settings under test are properly understood by testing engineer, then proceedings can be made to declare the relay unhealthy. Moreover, diagnosis can also be made through testing to determine whether any analogue, input/output module, CPU module, or power supply module is faulty. After identification and replacing the faulty module with the healthy one, the relay is to be tested again to ensure its healthiness.

In future, a detailed manual will be prepared which will include comprehensive testing procedural guidelines for understanding the complex design, features, and working of the numerical distance protection relay used for the protection of EHV transmission lines.

Author Contributions: Conceptualization, U.E., M.J. and U.J.; methodology, K.S.Z., A.U.R. and A.R.; validation, M.M.A., H.H. and M.S.; formal analysis, U.E., M.J. and U.J.; investigation M.M.A., H.H. and M.S.; resources, K.S.Z., A.U.R. and A.R.; data curation, M.M.A., H.H. and M.S.; writingoriginal draft preparation, U.E., M.J. and U.J.; writing — review and editing, M.M.A., H.H. and M.S., visualization, K.S.Z., A.U.R. and A.R.; supervision, K.S.Z., A.U.R. and A.R.; project administration M.M.A., H.H. and M.S. All authors have read and agreed to the published version of the manuscript. 
Funding: This work was supported by Taif University Researchers Supporting Project Number (TURSP-2020/328), Taif University, Taif, Saudi Arabia.

Institutional Review Board Statement: Not applicable.

Informed Consent Statement: Not applicable.

Data Availability Statement: As all the hardware testing were performed on differential relay installed for protection of 160 MVA, 220/132 kV Auto Transformer located at $220 \mathrm{kV}$ Grid Station NTDC Kala Shah Kaku, Lahore, Pakistan. Due to the privacy policy of the national grid, the data cannot be shared openly.

Acknowledgments: We deeply acknowledge Taif University for supporting this research through Taif University Researchers Supporting Project Number (TURSP-2020/328), Taif University, Taif, Saudi Arabia.

Conflicts of Interest: The authors declare no conflict of interest.

\section{References}

1. Bak, C.L.; Hansen, M.L.; Nissen, J.O. Distance protection in 150/60 kV transformer 60 kV feeders: Two real blackout case studies. J. Eng. 2018, 2018, 802-806. [CrossRef]

2. Khan, S.S.; Mehmood, K.T.; Hashmi, M.W.; Rafiq, M.A.; Sheikh, M.F. Power stability of 500/220/132 kV grid station system on single-line-to-ground fault at $500 \mathrm{kv}$ transmission lines. Sci. Int. J. 2015, 27, 3995-3999.

3. Akhmedova, O.; Soshinov, A.; Gazizov, F.; Ilyashenko, S. Development of an Intelligent System for Distance Relay Protection with Adaptive Algorithms for Determining the Operation Setpoints. Energies 2021, 14, 973. [CrossRef]

4. Verzosa, Q.; Lee, W.A. Testing Microprocessor-Based Numerical Transformer Differential Protection. IEEE Trans. Ind. Appl. 2017, 53, 56-64. [CrossRef]

5. Rocha, D.C.G.; Batista, W.H.; Coelho, A.L.M.; Araujo, M.R. Practical approach to testing the transformer differential protection for internal and external faults, CT saturation and inrush transients. J. Eng. 2018, 2018, 1239-1244. [CrossRef]

6. Andreev, M.; Suvorov, A.; Ruban, N.; Ufa, R.; Gusev, A.; Askarov, A.; Kievets, A.; Bhalja, B.R. Setting determination for numerical transformer differential protection via its detailed mathematical model. IET Gener. Transm. Distrib. 2020, 14, 1962-1972. [CrossRef]

7. Sevov, L.; Khan, U.; Zhang, Z. Enhancing Power Transformer Differential Protection to Improve Security and Dependability. IEEE Trans. Ind. Appl. 2017, 53, 2642-2649. [CrossRef]

8. Al-Ameri, S.M.; Kamarudin, M.S.; Yousof, M.F.M.; Salem, A.A.; Siada, A.A.; Mosaad, M.I. Interpretation of Frequency Response Analysis for Fault Detection in Power Transformers. Appl. Sci. 2021, 11, 2923. [CrossRef]

9. Al-Ameri, S.M.; Kamarudin, M.S.; Yousof, M.F.M.; Salem, A.A.; Banakhr, F.A.; Mosaad, M.I.; Abu-Siada, A. Understanding the Influence of Power Transformer Faults on the Frequency Response Signature Using Simulation Analysis and Statistical Indicators. IEEE Access 2021, 9, 70935-70947. [CrossRef]

10. Javed, U.; Mughees, N.; Jawad, M.; Azeem, O.; Abbas, G.; Ullah, N.; Chowdhury, M.S.; Techato, K.; Zaidi, K.S.; Tahir, U. A systematic Review of Key Challenges in Hybrid HVAC-HVDC Grids. Energies 2021, 14, 5451. [CrossRef]

11. So, E.; Verhoeven, R.; Simons, B.; Parks, H.V.; Angelo, D. A High-Precision Current Transformer for Loss Measurements of EHV Shunt Reactors. IEEE Trans. Instrum. Meas. 2019, 68, 1680-1687. [CrossRef]

12. Medeiros, R.P.; Costa, F.B. A Wavelet-Based Transformer Differential Protection with Differential Current Transformer Saturation and Cross-Country Fault Detection. IEEE Trans. Power Deliv. 2018, 33, 789-799. [CrossRef]

13. Ji, T.; Mo, C.; Zhang, L.L.; Wu, Q.H. Duty Cycle-Based Differential Protection Scheme for Power Transformers. IEEE Trans. Power Deliv. 2021. [CrossRef]

14. Prodan, C.; Rata, G. Apparatus for determining the clock hour figure of the vector group of the electrical transformers. In Proceedings of the IEEE International Conference and Exposition on Electrical and Power Engineering (EPE), Iasi, Romania, 18-19 October 2018; pp. 0259-0263.

15. Zhang, Z.; Mo, M.; Wu, C. Three-phase distribution transformer connections modeling based on matrix operation method by phase-coordinates. EURASIP J. Wirel. Commun. Netw. 2021, 2021, 66. [CrossRef]

16. Saeed, H.; Kamel, M.; Karrar, A.; Eltom, A.H.; Bowman, M. On-Site Low Voltage Determination of Zero-Sequence Impedances for Power Transformers. IEEE Trans. Power Deliv. 2020, 35, 1048-1057. [CrossRef]

17. Xu, H.; Domínguez-García, A.D.; Sauer, P.W. Optimal Tap Setting of Voltage Regulation Transformers Using Batch Reinforcement Learning. IEEE Trans. Power Syst. 2020, 35, 1990-2001. [CrossRef]

18. Mitra, J.; Xu, X.; Benidris, M. Reduction of Three-Phase Transformer Inrush Currents Using Controlled Switching. IEEE Trans. Ind. Appl. 2020, 56, 890-897. [CrossRef]

19. Ge, W.; Zhao, J.; Wang, Y. Analysis of the residual flux influence on inrush current and electromagnetic force in large power transformer. J. Eng. 2019, 2019, 2426-2429. [CrossRef]

20. Gunda, S.K.; Dhanikonda, V.S.S.S.S. Discrimination of Transformer Inrush Currents and Internal Fault Currents Using Extended Kalman Filter Algorithm (EKF). Energies 2021, 14, 6020. [CrossRef] 
21. Zheng, T.; Huang, T.; Ma, Y.; Zhang, Z.; Liu, L. Histogram-Based Method to Avoid Maloperation of Transformer Differential Protection Due to Current-Transformer Saturation under External Faults. IEEE Trans. Power Deliv. 2018, 33, 610-619. [CrossRef]

22. Shah, A.M.; Bhalja, B.R.; Patel, R.M.; Bhalja, H.; Agarwal, P.; Makwana, Y.M.; Malik, O.P. Quartile Based Differential Protection of Power Transformer. IEEE Trans. Power Deliv. 2020, 35, 2447-2458. [CrossRef]

23. Magrin, F.; Tavares, M.C. Increasing sensitivity for transformer protection using incremental differential. J. Eng. 2018, 2018, 1209-1215. [CrossRef]

24. GE Grid Solutions, P642: Transformer Protection IED, Technical Manual. Available online: https://www.gegridsolutions.com/ app /viewfiles.aspx?prod=P64X\&type=3 (accessed on 15 August 2021).

25. MiCOM S1 Agile Engineering Tool Suit (1.3.1), Alstom Grid. Available online: https://www.gegridsolutions.com/multilin/ catalog/engineering-tool-suite.htm (accessed on 5 August 2021).

26. Ameli, A.; Ghafouri, M.; Zeineldin, H.H.; Salama, M.M.A.; El-Saadany, E.F. Accurate Fault Diagnosis in Transformers Using an Auxiliary Current-Compensation-Based Framework for Differential Relays. IEEE Trans. Instrum. Meas. 2021, 70, 1-14.

27. IEEE Draft Standard for Common Format for Transient Data Exchange (COMTRADE) for Power Systems. In IEEE PC37.111/D4, January 2012 (IEC 60255-24 Ed.2); IEEE: Manhattan, MY, USA, 2012; pp. 1-72.

28. SEL-5030 SynchroWAVE Acselerator QuickSet Software, Schweitzer Engineering Laboratories, Inc. Available online: https: //selinc.com/products/5030/ (accessed on 10 August 2021). 